Journal for ImmunoTherapy of Cancer

\title{
Tumor rejection in $\mathrm{Cblb}^{-/-}$mice depends on IL-9 and Th9 cells
}

\author{
Oliver Schanz (1) , ${ }^{1}$ Isabelle Cornez, ${ }^{1}$ Sowmya Parampalli Yajnanarayana, ${ }^{1}$ \\ Friederike Sophie David, ${ }^{2,3}$ Sebastian Peer, ${ }^{4}$ Thomas Gruber, ${ }^{4}$ Peter Krawitz, ${ }^{2}$ \\ Peter Brossart, ${ }^{1}$ Annkristin Heine, ${ }^{1}$ Jenny Landsberg, ${ }^{5}$ Gottfried Baier, ${ }^{4}$ \\ Dominik Wolf ${ }^{1,6}$
}

To cite: Schanz 0, Cornez I, Yajnanarayana SP, et al. Tumor rejection in $\mathrm{Cblb}^{-/-}$mice depends on IL-9 and Th9 cells. Journal for ImmunoTherapy of Cancer 2021;9:e002889. doi:10.1136/jitc-2021-002889

- Additional supplemental material is published online only. To view, please visit the journal online (http://dx.doi.org/10. 1136/jitc-2021-002889).

OS, IC and SPY contributed equally.

Accepted 30 June 2021

\section{Check for updates}

(C) Author(s) (or their employer(s)) 2021. Re-use permitted under CC BY-NC. No commercial re-use. See rights and permissions. Published by BMJ.

${ }^{1}$ Oncology, Hematology, Immunoncology and Rheumatology, University Hospital Bonn, Bonn, Germany ${ }^{2}$ Institute for Genomic Statistics and Bioinformatics, University Hospital Bonn, Bonn, Germany ${ }^{3}$ Institute of Human Genetics, University Hospital Bonn, Bonn, Germany

${ }^{4}$ Institute of Translational Cell Genetics, Medical University of Innsbruck, Innsbruck, Austria

${ }^{5}$ Dermatology, University Hospital Bonn, Bonn, Germany ${ }^{6}$ Department of Internal Medicine V, Hematology and Oncology, and Tyrolean Cancer Research Institute (TKFI), Medical University of Innsbruck, Innsbruck, Austria

Correspondence to Professor Dominik Wolf; dominik.wolf@i-med.ac.at

\section{ABSTRACT}

Background Casitas B lymphoma-b (Cbl-b) is a central negative regulator of cytotoxic $T$ and natural killer (NK) cells and functions as an intracellular checkpoint in cancer. In particular, Th9 cells support mast cell activation, promote dendritic cell recruitment, enhance the cytolytic function of cytotoxic T lymphocytes and NK cells, and directly kill tumor cells, thereby contributing to tumor immunity. However, the role of $\mathrm{Cbl}-\mathrm{b}$ in the differentiation and antitumor function of Th9 cells is not sufficiently resolved.

Methods Using $\mathrm{Cblb}^{-/-}$mice, we investigated the effect of knocking out $C b / b$ on the differentiation process and function of different $T$ helper cell subsets, focusing on regulatory $T$ cell (Treg) and Th9 cells. We applied singlecell RNA (scRNA) sequencing of in vitro differentiated Th9 cells to understand how Cbl-b shapes the transcriptome and regulates the differentiation and function of Th9 cells. We transferred tumor-model antigen-specific $\mathrm{Cblb}^{-1-} \mathrm{Th} 9$ cells into melanoma-bearing mice and assessed tumor control in vivo. In addition, we blocked interleukin (IL)-9 in melanoma cell-exposed $\mathrm{Cblb}^{-/-}$mice to investigate the role of IL-9 in tumor immunity.

Results Here, we provide experimental evidence that Cbl-b acts as a rheostat favoring Tregs at the expense of Th9 cell differentiation. $\mathrm{Cblb}^{-1-}$ Th9 cells exert superior antitumor activity leading to improved melanoma control in vivo. Accordingly, blocking IL-9 in melanoma cell-exposed $\mathrm{Cblb}^{-1-}$ mice reversed their tumor rejection phenotype. Furthermore, scRNA sequencing of in vitro differentiated Th9 cells from naïve T cells isolated from wildtype and $\mathrm{Cblb}^{-/-}$animals revealed a transcriptomic basis for increased Th9 cell differentiation.

Conclusion We established IL-9 and Th9 cells as key antitumor executers in $\mathrm{Cblb}^{-1-}$ animals. This knowledge may be helpful for the future improvement of adoptive T cell therapies in cancer.

\section{BACKGROUND}

$\mathrm{CD}^{+} \mathrm{T}$ helper (Th) cells orchestrate adaptive and innate immune responses. They also mediate direct and indirect antitumor activity, even though their exact role in cancer is debatable. ${ }^{1}$ In 2008 IL-9-producing T helper (Th9) cells were defined as distinct Th cell lineage. ${ }^{2}$ Th9 cells resemble traditional Th2 cells and their differentiation depends on the transcription factors PU.1 and interferon regulatory factor 4 (IRF4). ${ }^{3} 4$ Several other transcription factors including signal transducer and activator of transcription (STAT) 5, STAT6, nuclear factor- $\kappa \mathrm{B}(\mathrm{NF}-\kappa \mathrm{B})$, nuclear factor of activated $\mathrm{T}$ cells (NFAT), interferon regulatory factor (IRF) 8 , forkhead box $\mathrm{O}$ 1, basic leucine zipper transcription factor (BATF), and BATF3 are also involved in interleukin (IL)-9 regulation. ${ }^{5-7}$ In addition, several cytokines have been shown to modulate IL-9 production (eg, IL-2, IL-25, IL-33 and thymic stromal lymphopoietin). ${ }^{8}$ Similarly, the tumor necrosis factor (TNF) family members OX40L, TNF-like cytokine (TL) $1 \mathrm{~A}$, glucocorticoid-induced tumor-necrosisfactor-receptor-related protein-ligand (GITRL) and TNF $\alpha$ promote Th9 cell differentiation and their antitumor efficacy. ${ }^{9-12}$ IL-9 can also be produced and released by mucosal mast cells, group 2 innate lymphoid cells, CD8 ${ }^{+} \mathrm{T}$ cells, regulatory $\mathrm{T}$ cells (Treg), $\mathrm{T}$ follicular helper cells and memory $\mathrm{B}$ cells. ${ }^{13-18}$ Of note, IL-9 initiates and regulates antitumor immunity via innate and adaptive immunity. ${ }^{19-21}$ In cancer, Th9 cells support mast cell activation, promote dendritic cell recruitment, enhance the cytolytic function of cytotoxic T lymphocytes (CTLs) and natural killer (NK) cells and directly kill tumor cells. However, IL-9 has also been shown to promote the immune-suppressive function of mast cells and Tregs. ${ }^{8}$ Furthermore, IL-9 can promote tumor progression in hematological tumors by acting as a lymphocyte growth factor. $^{22}$ Thus, IL-9 plays a dual role in tumor immunity.

Casitas B-lineage lymphoma protooncogene-b (Cbl-b) is a RING finger E3 ubiquitin-protein ligase with a broad spectrum of biological functions. Cbl-b belongs to the highly conserved $\mathrm{Cbl}$ ubiquitin ligase family. They consist of an N-terminal tyrosine kinase-binding (TKB) domain, a helical 
linker, a RING finger domain, the proline-rich (PR) motif and a C-terminal leucine zipper/ubiquitin-associated (UBA) domain. ${ }^{23}$ Cbl-b plays a central role in regulating adaptive immunity. ${ }^{24}{ }^{25}$ As such, Cbl-b negatively regulates T cell receptor (TCR), B cell receptor, CD40 and FcER1 signaling. ${ }^{26-30}$ Mechanistically, Cbl-b targets signaling proteins for ubiquitination or interacts with other proteins via its PR region and TKB or UBA domain. ${ }^{23}$ In $\mathrm{T}$ cells, Cbl-b acts as a prevention system for excessive $\mathrm{T}$ cell activation via the TCR. Cbl-b is highly expressed in $\mathrm{CD}^{+}$and $\mathrm{CD}^{+} \mathrm{T}$ cells and its expression levels in $\mathrm{T}$ cells are regulated by several co-stimulatory signals, including CD28 and CTL-associated protein 4 (CTLA4). ${ }^{31}{ }^{32}$ Maintenance of peripheral $\mathrm{T}$ cell tolerance is preserved by Cbl-b-induced restriction of CD28-dependent Vav-WASP signaling, involving actin reorganization and TCR clustering beyond other means. ${ }^{33}{ }^{34} \mathrm{Cblb}^{-/-} \mathrm{T}$ cells do not require CD28 co-stimulation for full activation and similar to programmed cell death protein 1 and CTLA4, Cbl-b acts as an immune checkpoint. $\mathrm{Cblb}^{-1-}$ animals rejected tumors in various models, ${ }^{35-39}$ which has been attributed to an increased number of interferon (IFN) $\gamma$-secreting $\mathrm{CD}^{+} \mathrm{T}$ cells, which are transforming growth factor (TGF) $\beta$ - or Treg-resistant. ${ }^{38-40}$ Ablation of Cbl-b results in enhanced cytotoxicity and higher IFN $\gamma$ and perforin release by NK cells, leading to increased NK cell-mediated cancer-killing. ${ }^{41}$ These observations make Cbl-b an attractive target candidate for improving cancerdirected immunotherapy.

In 2014, Qiao et al ${ }^{42}$ demonstrated that Cbl-b might be an ideal target for treating asthma, as it suppresses Th2 and Th9 cell differentiation, even though the study mainly focused on Th2 cells. Knowing the previously described critical role of both Cbl-b and IL-9 in antitumor immunity, we now evaluate in detail the role of Cbl-b in Th9-executed anti-cancer immunity. First, we show that Cbl-b profoundly modulates Th cell differentiation, by controlling the balance between Th9 and Treg cell differentiation. Second, we deconvoluted the transcriptional impact of Cblb deletion at the single-cell level in Th9 cells, which favored the generation of more potent antitumor reactive Th9 cells. Finally, we demonstrated that tumor control in $\mathrm{Cblb}^{-1-}$ mice depends on IL-9 levels. Targeting Cbl-b to generate more potent anti-cancer reactive Th9 cells might represent a new therapeutic strategy to improve anti-cancer immunotherapy.

\section{METHODS}

\section{In vitro differentiation of naïve $\mathrm{CD4}^{+} \mathrm{T}$ cells}

Naive $\mathrm{T}$ cells, isolated from mouse splenocytes, were seeded at a concentration of $1.5 \times 10^{\wedge} 5$ cells/well in 96-well round-bottom plates and activated with platebound anti-CD3 $(3 \mu \mathrm{g} / \mathrm{mL})$ and soluble anti-CD28 $(5 \mu \mathrm{g} /$ $\mathrm{mL}$ ) in RPMI 1640 medium supplemented with $10 \%$ FBS, $1 \% \mathrm{P} / \mathrm{S}$, and $0.1 \% \beta$-mercaptoethanol. The cells were polarized into Th9 cells (3ng/mL hTGF $\beta$, $20 \mathrm{ng} /$ $\mathrm{mL}$ IL-4 and $20 \mu \mathrm{g} / \mathrm{mL}$ anti-IFN $\gamma)$, Treg $(5 \mathrm{ng} / \mathrm{mL}$ hTGF $\beta$ and $100 \mathrm{U} / \mathrm{mL}$ IL-2), Th1 cells $(10 \mathrm{ng} / \mathrm{mL} \mathrm{IL}-12$, $50 \mathrm{U} /$ $\mathrm{mL}$ IL-2, $10 \mu \mathrm{g} / \mathrm{mL}$ anti-IL-4), Th2 cells $(20 \mathrm{ng} / \mathrm{mL}$ IL-4, $50 \mathrm{U} / \mathrm{mL}$ IL-2, $10 \mu \mathrm{g} / \mathrm{mL}$ IL-12) or Th17 cells $(1 \mathrm{ng} / \mathrm{mL}$ hTGF $\beta, 50 \mathrm{ng} / \mathrm{mL}$ IL- $6,10 \mathrm{ng} / \mathrm{mL}$ IL- $1 \beta, 10 \mu \mathrm{g} / \mathrm{mL}$ antiIFN $\gamma, 10 \mu \mathrm{g} / \mathrm{mL}$ anti-IL-4) for 48 hours, 72 hours or 5 days.

\section{Proliferation assay}

To analyze the proliferation of Th9 and Treg cells, freshly isolated naive $\mathrm{CD} 4^{+} \mathrm{T}$ cells from mouse splenocytes were stained with $0.5 \mu \mathrm{M}$ carboxyfluorescein succinimidyl ester (CFSE)-PB. CFSE-stained naïve $\mathrm{CD} 4^{+} \mathrm{T}$ cells were seeded at $1 \times 10^{\wedge} 5$ cells per well in 96 -well flat-bottom plates and differentiated for 3 days into Th9 cells (plate-bound antiCD3 $(3 \mu \mathrm{g} / \mathrm{mL})$, anti-CD28 $(5 \mu \mathrm{g} / \mathrm{mL}), 3 \mathrm{ng} / \mathrm{mL}$ hTGFß, $20 \mathrm{ng} / \mathrm{mL}$ IL- 4 and $20 \mu \mathrm{g} / \mathrm{mL}$ anti-IFN $\gamma)$ or Treg cells (plate-bound anti-CD3 $(3 \mu \mathrm{g} / \mathrm{mL})$, anti-CD28 $(5 \mu \mathrm{g} / \mathrm{mL})$, $5 \mathrm{ng} / \mathrm{mL} \mathrm{hTGF} \beta$ and $100 \mathrm{U} / \mathrm{mL}$ IL-2). The proliferation was quantified by analysis of CFSE dilution using flow cytometry.

\section{Flow cytometry}

In vitro differentiated $\mathrm{CD}^{+} \mathrm{T}$ cells, isolated tumorinfiltrating lymphocytes, and lymph node cells were stained with antibodies against CD3 (145-2 C11), CD4 (RM4-5), CD8 $\alpha$ (53-6.7), CD11c (HL-3), TCR $\beta$ chain (H57-597), TCR $\gamma \delta$ (GL3), Foxp3 (FJK16s), CD45 (30F11), IFN $\gamma$ (XMG1.1), IL-13 (eBio13A), IL-9 (RM9A4), IL-17A (eBio17B7), IRF4 (IRF4.3E4), PU.1 (7C2C34), CD25 (PC61), CD44 (IM7) CD62L (MEL-14). Antibodies were purchased from eBioscience (San Diego, USA) or BioLegend (San Diego, USA). For intracellular cytokine and transcription factor analysis, cells were fixed with $2 \%$ paraformaldehyde for $20 \mathrm{~min}$, permeabilized with $0.5 \%$ saponin in PBS/BSA, and stained for $30 \mathrm{~min}$ at room temperature in the dark. Populations were analyzed with a BD FACSCanto II flow cytometer, and data were analyzed using FlowJo software (TreeStar, Ashland, USA).

\section{Real-time PCR-analysis}

According to the manufacturer's instructions, RNA from tumor tissue, isolated lymphocytes, or in vitro differentiated T cells was isolated using the Qiagen RNeasy kit or the Zymo Research quick-RNA miniprep kit. The RNA concentration was determined using the NanoDrop 2000 system. According to the manufacturer's instructions, the first-strand cDNA was synthesized using a RevertAid first strand cDNA synthesis kit from Thermo Fisher Scientific or High capacity cDNA reverse transcription kit (Applied Biosystems). Quantitative real-time PCR was performed using SYBR Green PCR Master Mix (Applied Biosystems) on the Mastercycler RealPlex2 (Eppendorf) and the LightCycler 480 real-time PCR system (Roche Diagnostics). Primers were designed using the Universal Probe Library (Roche Applied Science, Mannheim, Germany) and were purchased from Invitrogen.

\section{Cell culture}

The HCmel3 cell line was first generated from a primary murine melanoma in which the hepatocyte growth factor 
is overexpressed and the p16lnk4a-dependent cell cycle regulation is impaired due to an oncogenic CDK4 (R24C) germline mutation. Landsberg et a $t^{43} \mathrm{HCmel} 3$ melanoma cells were routinely cultured in RPMI 1640 medium (Life Technologies) supplemented with 10\% FCS (Biochrome), $2 \mathrm{mM}$ L-glutamine, $10 \mathrm{mM}$ non-essential amino acids, $1 \mathrm{mM}$ HEPES (all from Life Technologies), $20 \mu \mathrm{M}$ 2-mercaptoethanol (Sigma), $100 \mathrm{IU} / \mathrm{mL}$ penicillin and $100 \mu \mathrm{g} / \mathrm{mL}$ streptomycin (Invitrogen). B16-OVA cells were cultured in RPMI 1640 medium supplemented with $10 \%$ FCS, $1 \%$ penicillin-streptomycin, $0.4 \mathrm{mg} / \mathrm{mL}$ G418 (Sigma). Cells were cultured under sterile conditions at $37^{\circ} \mathrm{C}$ and $5 \%$ carbon dioxide in a water-saturated atmosphere.

\section{Tumor experiments}

For HCmel3 tumor transplantation experiments, $200 \mu \mathrm{g}$ of InVivoMAb anti-mouse IL-9 (9C1) or InVivoMAb mouse IgG2a isotype control (both Bio X Cell) was intravenously administered to mice for three consecutive days starting from the day before tumor injection (day $-1,0$, $1)$. HCmel3 cells $\left(4 \times 10^{\wedge} 5\right)$ were injected intracutaneously into the right flank on day 0 . Anti-IL-9 or control IgG was administered intravenously to the respective mice every third day. Tumor size was measured two times per week using a caliper. Mice were sacrificed when the tumor volume reached $1 \mathrm{~cm}^{3}\left(0.5 \times\right.$ length $\times$ width $\left.{ }^{2}\right)$ or when other criteria requiring euthanasia were reached. For B16-OVA tumor transplantation experiments, C57BL/6N mice were injected intracutaneously with $1 \times 10^{\wedge} 5$ B16OVA cells in the right flank. On days 5 and 9 post tumor injection, in vitro generated Th9 cells $\left(3 \times 10^{\wedge} 6\right)$ from OT-II and OT-II* $\mathrm{Cblb}^{-/-}$mice were injected intravenously. Tumor size was measured every other day using a caliper. Mice were sacrificed when the tumor volume reached 1 $\mathrm{cm}^{3}\left(0.5 \times\right.$ length $\times$ width $\left.{ }^{2}\right)$ or when signs of illness were observed.

\section{Measuring cytokine levels}

Cytokine levels were measured in cell culture supernatants that were either freshly processed or stored at $-80^{\circ} \mathrm{C}$ prior to analysis. Cytokine measurements were performed using different BD Cytometric Bead Array Flex Sets against murine IFN $\gamma$, IL-13, IL-9, IL-2, or TNF $\alpha$.

\section{Single-cell RNA sequencing}

Th9 cells were generated in vitro from naïve $\mathrm{CD} 4^{+} \mathrm{T}$ cells isolated from the murine spleen using a naive $\mathrm{CD} 4^{+}$ $\mathrm{T}$ cell isolation kit from Miltenyi Biotec. Cells from six samples in total ( $3 \times$ wildtype (WT), $3 \times \mathrm{Cblb}^{-/-}$) were polarized into Th9 cells $(3 \mathrm{ng} / \mathrm{mL}$ hTGF $\beta, 20 \mathrm{ng} / \mathrm{mL}$ IL-4 and $20 \mu \mathrm{g} / \mathrm{mL}$ anti-IFN $\gamma$ ) for 48 hours, purified using CD4 (L3T4) MicroBeads from Miltenyi Biotec, and transferred to the Next Generation Sequencing Core Facility of the University Hospital Bonn for single-cell RNA (scRNA) sequencing. According to the manufacturer's specifications, a library was prepared using the $10 \times$ Genomics Single Cell 3' reagent Kits V.3. Sequencing was performed using an Illumina NovaSeq 6000 Sequencing System, which generated $26 \mathrm{nt}$ barcode reads as well as $98 \mathrm{nt}$ transcript reads (contrary to manufacturer's recommendations of $28 \mathrm{nt}$ and $91 \mathrm{nt}$, respectively), aiming for 7500 cells per sample with a sequencing depth of approximately 80,000 reads per cell. Data analysis and visualization were performed by FSD using multiple tools and R/ Bioconductor packages.

\section{Generation of nuclear, cytosolic and whole cell extracts}

Cells were harvested, washed once with cold PBS, (1 min, $\left.9300 \mathrm{rcf}, 4^{\circ} \mathrm{C}\right)$ resuspended in $90 \mu \mathrm{l}$ Buffer A $(10 \mathrm{mM}$ HEPES $\mathrm{pH}$ 7.9; $10 \mathrm{mM}$ KCl; $0.1 \mathrm{mM}$ EDTA; $0.1 \mathrm{mM}$ EGTA; $1 \mathrm{mM}$ DTT; $0.5 \mathrm{mM}$ PMSF) and kept on ice for $15 \mathrm{~min}$. Next, $6 \mu \mathrm{l}$ of $10 \% \mathrm{NP}-40$ (final concentration 0.63\%) was added, and the pellet was vortexed thoroughly and centrifuged $\left(5 \mathrm{~min}, 2300 \mathrm{rcf}, 4^{\circ} \mathrm{C}\right)$. The supernatant was collected for the cytosolic protein fraction, and the remaining nuclear pellet was washed twice with $300 \mu \mathrm{l}$ Buffer A (5 min, $\left.2300 \mathrm{rcf}, 4^{\circ} \mathrm{C}\right)$. The supernatant was discarded, $30 \mu \mathrm{l}$ Buffer C $(20 \mathrm{mM}$ Hepes $\mathrm{pH}$ 7.9; $0.4 \mathrm{M}$ NaCl; 1 mM EDTA; 1 mM EGTA; 1 mM DTT; 1 mM PMSF) was added to the pellet, and put on a shaker for $30 \mathrm{~min}$ at $4^{\circ} \mathrm{C}$. After centrifugation $\left(10 \mathrm{~min}, 13,000 \mathrm{rcf}, 4^{\circ} \mathrm{C}\right)$ the supernatant was collected for the nuclear protein fraction. For whole-cell protein lysates, cells were collected, washed once with cold PBS (1 min, $9300 \mathrm{rcf}, 4^{\circ} \mathrm{C}$ ) and lysed in $30 \mu \mathrm{l}$ lysis buffer $\left(5 \mathrm{mM} \mathrm{Na}_{4} \mathrm{P}_{2} \mathrm{O}_{7}, 5 \mathrm{mM} \mathrm{NaF}, 1 \mathrm{mM}\right.$ $\mathrm{Na}_{3} \mathrm{VO}_{4}, 5 \mathrm{mM}$ EDTA, $150 \mathrm{mM} \mathrm{NaCl}, 50 \mathrm{mM}$ Tris ( $\left.\mathrm{pH} 7.3\right)$, $1 \% \mathrm{NP}-40$, aprotinin, and leupeptin $(50 \mu \mathrm{g} / \mathrm{mL}$ each $)$ ) for $30 \mathrm{~min}$ on ice. After centrifugation $\left(15,000 \mathrm{rcf}, 4^{\circ} \mathrm{C}\right)$, the supernatant was collected for protein lysates.

\section{Western blotting}

Pierce Lane Marker Reducing Sample Buffer (3900) was added to the samples and western blotting analysis with antibodies against NFATc1 (Santacruz 7294; dilution 1:1000), Cbl-b (Abcam 54362; dilution 1:1000), PU.1 (Cell Signaling Technology 2266, 1:1000), IRF4 (Cell Signaling Technology 4964, 1:1000), GAPDH (Cell Signaling Technology 5174, 1:1000), actin (Santacruz 1615; dilution 1:2000) or lamin B1 (abcam16048; dilution 1:10,000) was performed. In addition, densitometric analysis was performed using the ImageJ software.

\section{Statistical methods}

Sample size for animal experiments was determined with the G*Power software during initial study design. The number of performed experiments and used mice or biological replicates, which equals cells taken from one mouse, are stated in the figure legends. Statistical analysis was performed using the unpaired Student's t-test if only two independent groups or two conditions in one experimental group were compared. One-way analysis of variance (ANOVA) was used to determine any statistical differences between three or more independent experimental groups. Two-way ANOVA was used to analyze the mean differences between groups 
that were split into two independent variables. All data are presented as mean \pm SEM unless stated otherwise in the figure legend. Significance was defined at $* \mathrm{p}<0.05$, $* * \mathrm{p}<0.01, * * * \mathrm{p}<0.001$, and $* * * * \mathrm{p}<0.0001$. All statistical analyses were conducted with the software GraphPad Prism.

\section{In vitro killing assay of B16 tumor cells}

OT-II and OT-II* $\mathrm{Cblb}^{-/-}$naïve $\mathrm{CD} 4^{+} \mathrm{T}$ cells were polarized in vitro into Th9 cells for 48 hours. B16-OVA and B16-WT tumor cells were labeled with CFSE, mixed at a 1:1 ratio, and seeded into 96-well plates (50,000 cells/well; 25,000 CFSE low B16-OVA and 25,000 CFSE high B16-WT). Th9 cells $(100,000)$ were added and incubated for 16 hours. The degree of dead/killed B16-OVA and B16-WT cells was determined through usage of flow cytometry and the Zombie Fixable Viability Kit from BioLegend, bringing living and dead cells into proportion.

\section{Histology}

Mouse tumor samples were immersed in a zinc-based fixative (BD, Franklin Lakes, USA). Tissues were embedded in paraffin and sections $(4 \mu \mathrm{m})$ stained with $\mathrm{H} \& \mathrm{E}$ according to standard protocols. Immunohistochemistry was also performed on $4 \mu \mathrm{m}$ paraffin sections. Melanomas were bleached before staining $\left(20 \mathrm{~min}\right.$ at $37^{\circ} \mathrm{C}$ in $30 \% \mathrm{H}_{2} \mathrm{O}_{2}$ and $0.5 \% \mathrm{KOH}, 20 \mathrm{~s}$ in $1 \%$ acetic acid and 5 min in Tris buffer). The sections were dried overnight at $37^{\circ} \mathrm{C}$ and rehydrated through a graded alcohol series. Sections were bleached for $20-40 \mathrm{~min}$ in $3 \% \mathrm{H}_{2} \mathrm{O}_{2}$ with $\mathrm{KOH}$ and washed afterwards with TBS buffer. All sections were heat-pretreated in a citrate buffer $(\mathrm{pH} 6)$ for $10 \mathrm{~min}$ at $95^{\circ} \mathrm{C}-99^{\circ} \mathrm{C}$ to eliminate potential antigen blockings and washed afterwards with TBS buffer. The sections were incubated with anti CD45 mAb (30-F11) from BD Pharmingen at $25^{\circ} \mathrm{C}$ for 1 hour (1:500) in a staining chamber and a secondary polyclonal rabbit anti-Rat Immunoglobulins Biotinylated (Dako). The Dako Real Detection System (Dako, California, USA) was used for the detection of immunoreactivity.

\section{Animal experimentation}

All mice used for this study were housed under specific pathogen free conditions in the 'Haus für Experimentelle Therapie' at the University Hospital Bonn. All animal experiments performed in this study have been approved by the 'Landesamt für Natur, Umwelt und Verbraucherschutz Nordrhein-Westfalen' under the file reference number '81-02.04.2017.A418'. When planning and carrying out experiments, we strictly followed the $3 \mathrm{R}$ principle (replacement, reduction, refinement). Close monitoring of the mice with regular clinical scoring, observation of tumor growth and weight was performed. Animal treatment as well as termination criteria are in unison with the specifications of the Society of Laboratory Animal Science (GV-SOLAS).

\section{RESULTS}

Cbl-b regulates $\mathrm{T}$ helper cell differentiation from naïve $\mathrm{CD4}^{+} \mathrm{T}$ cells in vitro

It is well established that $C b l b$ is expressed in and controls the activation threshold of $\mathrm{CD} 4^{+}$T cells. ${ }^{44}$ The expression levels of Cblb during the differentiation process of $\mathrm{T}$ cell subpopulations, particularly Treg and Th9 cells, have not been analyzed in detail. After 48 hours and 72 hours of differentiation, Th9 cells showed significantly lower Cblb messenger RNA (mRNA) expression levels than Th0 cells (figure 1A). This observation was even more impressive when analyzing protein levels, as Th0 cells and Treg cells showed strong expression of Cbl-b, while this was virtually undetectable in Th9 cells after 48 hours and 72 hours of differentiation (figure 1B). Thus, we next validated whether regulation of Cbl-b is also functionally involved in the regulation of $\mathrm{T}$ helper $(\mathrm{Th})$ cell subset differentiation. Therefore, we generated Th1, Th2, Th9, Treg, and Th17 cells from naïve $\mathrm{CD}_{4}^{+} \mathrm{T}$ cells isolated from WT or $\mathrm{Cblb}^{-/-}$mice, respectively. After 48 hours and 72 hours Th cells were analyzed by flow cytometry, with intracellular staining for the subset-typical hallmark cytokines IFN $\gamma$, IL-13, IL-9, IL-17 and the transcription factor forkhead box P3 (Foxp3) (online supplemental figures 1 and 2). A thorough analysis of the cytokine-positive cell subsets revealed considerable differences between the WT and $\mathrm{Cblb}^{-/-}$Th cell subsets. Differentiation of Th1 and Th17 cells led to broadly similar frequencies of IFN $\gamma$ and IL-17 positive cells, with more IFN $\gamma^{+}$cells in the absence of $\mathrm{Cblb}$ after 72 hours of Th1 cell differentiation (online supplemental figure 2C). As previously reported, ${ }^{42}$ loss of Cblb favored Th2 differentiation, mirrored by a significantly higher frequency of IL-13 ${ }^{+}$cells and higher Il13 mRNA expression levels (online supplemental figure 2B-D). However, the most significant differences between WT and $\mathrm{Cblb}^{-1-}$ mice could be observed in the differentiation of Treg and Th9 cells (online supplemental figure 2 and figure 1). Th9 cultures from $\mathrm{Cblb}^{-1-}$ mice displayed a significantly higher frequency of IL- $9^{+}$and IL- $13^{+}$cells, whereas the frequency of $\mathrm{CD} 25^{+} \mathrm{Foxp}^{+}{ }^{+}$Tregs was significantly lower when compared with Th9 cultures generated from WT T cells (figure 1C,D). This observation was slightly more pronounced at 48 hours than at 72 hours, indicating that knocking out Cblb might change the Th9 cell differentiation dynamics during the early differentiation phase (online supplemental figure 2 ). In line with the protein data, $\mathrm{Cblb}^{-1-} \mathrm{Th} 9$ cells showed significantly higher $I l 9$ mRNA expression levels (figure $1 \mathrm{E}$ and online supplemental figure 2C) and released more IL-9 and IL-13 into the cell culture supernatant (figure $1 \mathrm{~F}$ and online supplemental figure 3). Besides Th9 cells, also Treg cell cultures from $\mathrm{Cblb}^{-/-}$mice differed markedly from those of WT mice, as they contained a significantly lower frequency of $\mathrm{CD} 25^{+} \mathrm{Foxp}^{+}$Treg, whereas the frequency of IFN $\gamma^{+}$ and IL $-9^{+}$cells was significantly higher in these cultures, an effect that was visible after 48 hours and even more pronounced after 72 hours (figure 1 and online supplemental figure 2B). Lower Foxp3 mRNA expression levels 
A

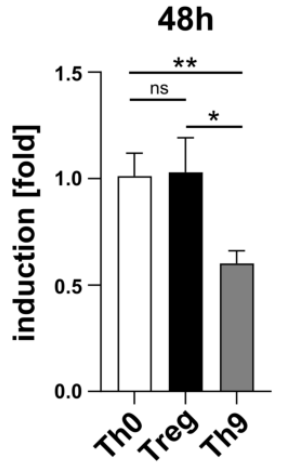

C

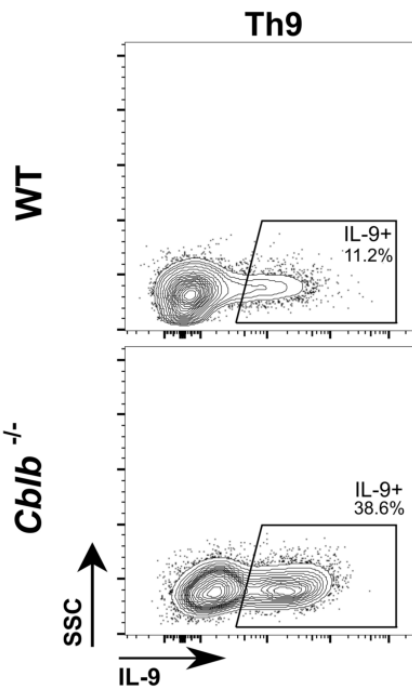

E

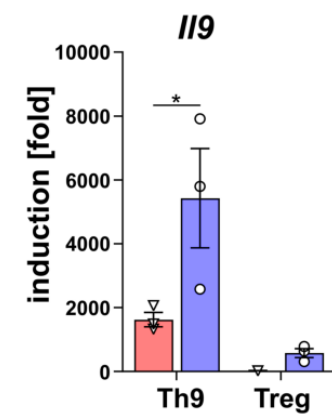

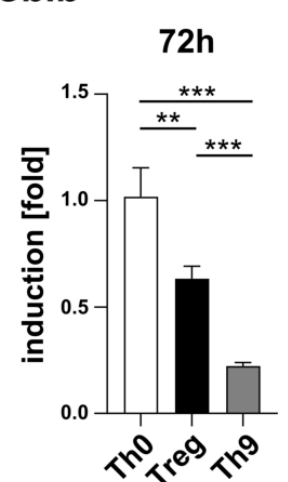

B

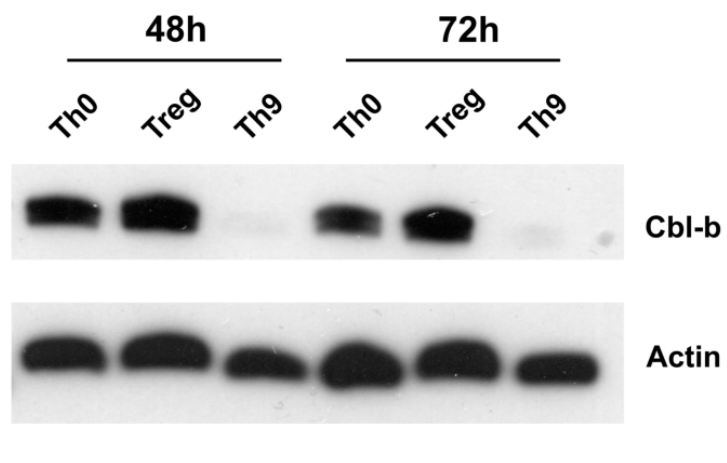

Figure $1 \mathrm{Cbl}-\mathrm{b}$ expression is downregulated in Th9 cells and Cbl-b deficiency leads to enhanced Th9 cell and reduced Treg differentiation in vitro. Naïve (CD4 $\left.{ }^{+} \mathrm{CD} 62 \mathrm{~L}^{+} \mathrm{CD} 44^{-}\right) \mathrm{T}$ cells from WT and $\mathrm{Cbl}-\mathrm{b}^{-/-}$mice are differentiated for $48 \mathrm{hours}$ or $72 \mathrm{hours}$ in the presence of a defined cocktail of cytokines and functional antibodies. (A) Cblb expression in Th0, Treg and Th9 cells is determined by qPCR after 48 hours and 72 hours of differentiation. (B) Western blot analysis of Cbl-b and Actin protein expression after 48 hours and 72 hours of Th0, Treg or Th9 differentiation. (C)The frequency of Th9 and Treg cells is determined by flow cytometry, performing an intracellular staining of the signature cytokine or transcription factor of the respective subset $\left(\mathrm{IL}-9^{+}\right.$, CD25 ${ }^{+}$Foxp $3^{+}$). Cells are gated on living CD45 ${ }^{+}$cells. (D) Frequency of IFN $\gamma$, IL-13, IL-9, CD25/Foxp3 and IL-17 positive cells in Th9 and Treg cultures was determined after 48 hours. (E) //9 and Foxp3 expression by in vitro differentiated Th9 and Treg cells was determined after 48 hours by qPCR and fold induction was determined by the ddtc method using the housekeeping gene GAPDH. (F) The concentration of IFN $\gamma$, IL-13, IL-9, IL-2 and TNF $\alpha$ was determined in the cell culture supernatant after 48 hours of differentiation using the BD Cytometric Bead Array. Data is representative of at least three independent experiments $(B / C)$ or pooled from at least two independent experiments $(n=2-11$ biological replicates). Results are shown as mean \pm SEM and significance was calculated by multiple unpaired t-tests $(A)$ and two-way analysis of variance and multiple comparison test, corrected by Sidak post hoc analysis, as recommended by GraphPad Prism software $\left({ }^{*} p<0.05,{ }^{* *} p<0.01,{ }^{* * *} p<0.001\right.$, $\left.{ }^{\star * \star \star} \mathrm{p}<0.0001\right)$. Cbl-b, casitas B-lineage lymphoma proto-oncogene-b; Foxp3, forkhead box P3; IFN, interferon; IL, interleukin; qPCR, quantitative PCR; Treg, regulatory T cells; WT, wildtype. 
were also measured in $\mathrm{Cblb}^{-/-}$Treg cells collected after 72 hours of differentiation (online supplemental figure 2C). $\mathrm{Cblb}^{-/-}$Tregs further released a diverse array of cytokines into the culture supernatant (IFN $\gamma$, IL-9, IL-2, and $\mathrm{TNF} \alpha$ ), which could not be observed for WT Treg cells, suggesting that these cells might be less suppressive compared with WT Treg cells (online supplemental figure $3 \mathrm{~A}, \mathrm{~B})$. Of note $\mathrm{TNF} \alpha$ showed a generally higher concentration in all Th cell subsets generated from $\mathrm{Cblb}^{-/-}$ naïve $T$ cells, although this difference was only significant under Th1 polarizing conditions (online supplemental figure $3 \mathrm{C}$ ). Taken together, we observed that deletion of Cblb favored Th9 cell differentiation. This was paralleled by a clearly lower Treg frequency, indicating a potential role of $C b l b$ as a switch in the polarization between Th9 and Treg cells.

\section{Increased IL-9 secretion by $\mathrm{Cblb}^{-1-} \mathrm{T}$ cells suppresses Treg differentiation}

Based on our hypothesis that Cbl-b acts as a specific switch in the regulation of Th9 versus Treg differentiation, we speculated that the elevated levels of IL-9 in the $\mathrm{Cblb}^{-/-}$ Treg cultures might be involved in the suppression of Foxp3 expression and consequently Treg differentiation. Therefore, we performed in vitro Treg differentiation for 72 hours in the presence of 5,10 , or $20 \mu \mathrm{g} / \mathrm{mL}$ neutralizing anti-IL-9 antibodies. Under normal circumstances, WT Treg cultures produced $80 \%$ CD25 ${ }^{+} \mathrm{Foxp}^{+}$cells and $\mathrm{Cblb}^{-/-}$cultures produced less than $40 \%$ CD25 $5^{+} \mathrm{Foxp}^{+}$ cells; blocking IL-9 increased the frequency of Treg cells in the $\mathrm{Cblb}^{-1-}$ cultures with increasing concentration of the neutralizing antibody (figure 2A,C). Blocking IL-9 in WT Treg cultures led to a slight but insignificant lowering of the frequency of Treg cells, while the frequency of Tregs in $\mathrm{Cblb}^{-1-}$ samples treated with 10 or $20 \mu \mathrm{g} / \mathrm{mL}$ anti-IL-9 antibody reached approximately the same level as in WT samples. Similarly, the frequency of Treg cells and the expression of Foxp3, which decreased in $\mathrm{Cblb}^{-1-}$ Tregs, could be restored to WT levels by neutralizing IL-9 (figure 2A,B). Neither knocking out Cblb nor blocking IL-9 had any influence on the expression of CD25 (figure 2C). We next wondered whether, besides influencing the frequency, knocking out Cblb or blocking IL-9 also leads to functional impairment of Treg cells. Therefore, naïve WT or $\mathrm{Cblb}^{-1-} \mathrm{CD} 4^{+} \mathrm{T}$ cells were polarized into Treg cells in the presence or absence of a neutralizing anti-IL-9 antibody $(20 \mu \mathrm{g} / \mathrm{mL})$. Treg cells were then sorted $\left(\mathrm{CD} 4^{+} \mathrm{CD} 25^{\text {hi }} \mathrm{CD} 45 \mathrm{RB}^{\text {low }}\right)$ and co-cultured with CD3-depleted splenocytes and CFSE-stained WT CD4 ${ }^{+}$ conventional $\mathrm{T}$ cells at a 1:1:1 ratio. While control cells showed robust proliferation (as indicated by CFSE dilution), WT, $\mathrm{Cblb}^{-/-}$and anti-IL-9-treated Treg cells inhibited proliferation efficiently and showed no functional impairment (figure 2D,E). Taken together, these results indicate that Cbl-b suppresses the production and release of IL-9 by T cells, and that high levels of IL-9, as observed in $\mathrm{Cblb}^{-/-}$cells, inhibit in trans Treg differentiation, without affecting their suppressive function.

\section{Enhanced Th9 cell differentiation in $\mathrm{Cblb}^{-/-} \mathrm{T}$ cells is not mediated by NFAT}

$\mathrm{Cblb}^{-/-} \mathrm{T}$ cells are hyper-responsive mirrored by a lower TCR activation threshold that does not require CD28 co-stimulation when TCR is ligated. ${ }^{44}$ The transcription factor family, known as the nuclear factor of activated $\mathrm{T}$ cells (NFATs), governs gene expression that regulates $\mathrm{T}$ cell development and differentiation. To assess whether enhanced Th9 cell differentiation could be due to a lower TCR activation threshold mediated by NFAT, we investigated the expression of NFAT proteins as well as the NFAT nuclear entry in Th9 cells and cells stimulated only with CD3/28 (Th0) from WT and $\mathrm{Cblb}^{-/-}$mice. The expression of NFATc1, NFATc1 alphaP1, NFATc1 betaP2 and NFATc 2 was generally higher in Th9 cells than in Th0 cells; however, their expression in $\mathrm{Cblb}^{-1-}$ Th9 samples was slightly but not significantly lower, except for NFATc1, which was significantly decreased in $\mathrm{Cblb}^{-/-} \mathrm{Th} 9$ cells compared with WT Th9 cells (online supplemental figure 4A). In addition, we did not observe higher protein expression levels of NFATc1 in $\mathrm{Cblb}^{-/-}$Th9 cells compared with WT Th9 cells, either in the nucleus or in the cytosol, as well as no higher NFATc1 levels in the nucleus compared with the cytosol, which would have indicated a higher degree of nuclear entry or nuclear activity (online supplemental figure $4 \mathrm{~B}-\mathrm{E}$ ). This set of data collectively rules out that stronger Th9 cell differentiation of $\mathrm{Cblb}^{-/-} \mathrm{T}$ cells is just a function of a lower TCR activation threshold mirrored by induced NFAT signaling.

\section{Proliferation of $\mathrm{Cblb}^{-1-}$ Th9 cells and their IRF4 and PU.1 expression}

Previous studies have reported an increased proliferation rate of $\mathrm{Cblb}^{-1-} \mathrm{T}$ cells due to a lower TCR activation threshold ${ }^{36}$ Hence, we assessed whether the increased frequency of IL-9 ${ }^{+}$cells in Th9 cultures from $\mathrm{Cblb}^{-/-}$mice resulted from hyperproliferation. In line with previous findings, $\mathrm{Cblb}^{-1-}$ Th9 cells showed higher proliferation rates. Strikingly, the CD4 $4^{+}$IL- $9^{+}$population in WT and $\mathrm{Cblb}^{-/-}$Th9 cells was found to proliferate at a similar rate, while CD $4^{+} \mathrm{IL}-9^{-}$cells from $\mathrm{Cblb}^{-/-}$cultures showed a much higher degree of proliferation compared with CD4 $4^{+}$IL-9 ${ }^{-}$cells from WT cultures (figure 3A). Strikingly, no differences in proliferation in Treg cultures, when looking seperately at CD25 $5^{+}$Foxp $3^{+}$and Foxp3 ${ }^{-}$ cells could be observed. Moreover, we observed that the mean fluorescence intensity levels of IL-9 in CD $4^{+}$IL- $-9^{+}$ cells were significantly higher in $\mathrm{Cblb}^{-/-}$mice than in WT mice (figure 3B), indicating a higher production of IL-9 in absence of Cbl-b. The transcription factors PU.1 and IRF4 have been described to be essential for Th9 development. ${ }^{3}{ }^{4}$ Accordingly, we assessed the expression of IRF4 and PU.1 (SPI1) after 3, 6, 24 and 48 hours of Th9 cell differentiation (figure 3). WT and $\mathrm{Cblb}^{-1-}$ Th9 cells similarly upregulated IRF4 after 3 and 6 hours of differentiation, followed by a slow decline (figure 3C). SPI1 expression, which has been shown to be required for optimal IL-9 production in mouse T cells, ${ }^{3}$ was initially present in 

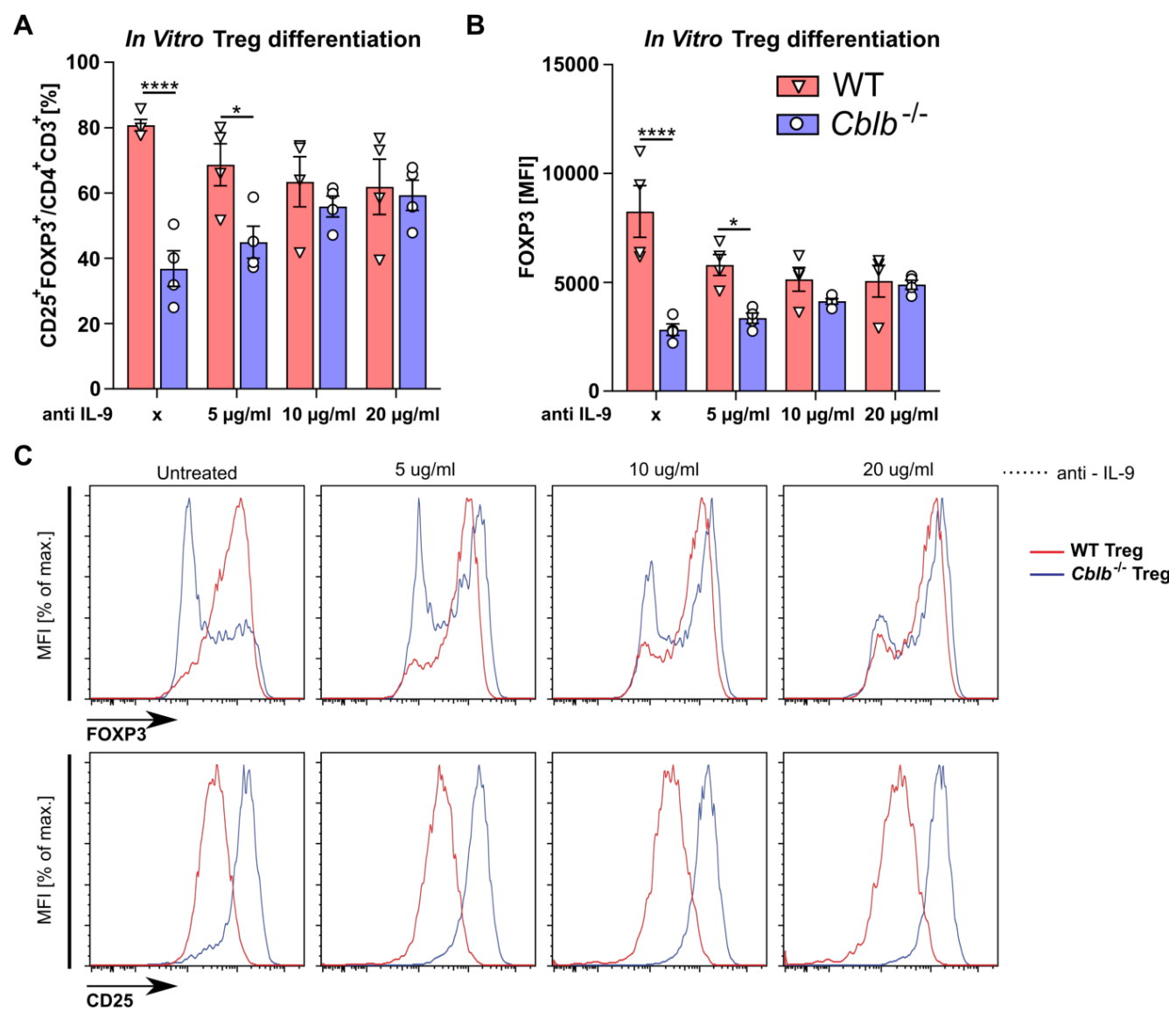

D Treg suppression assay
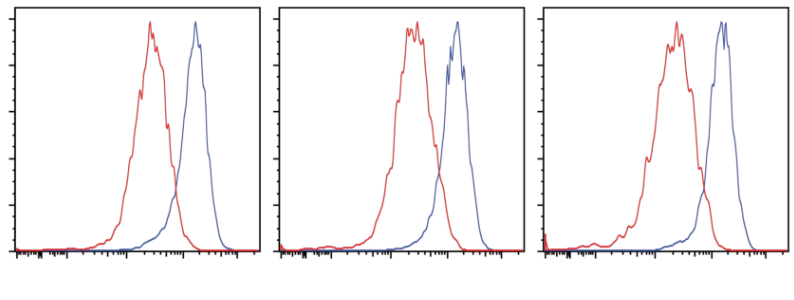

E
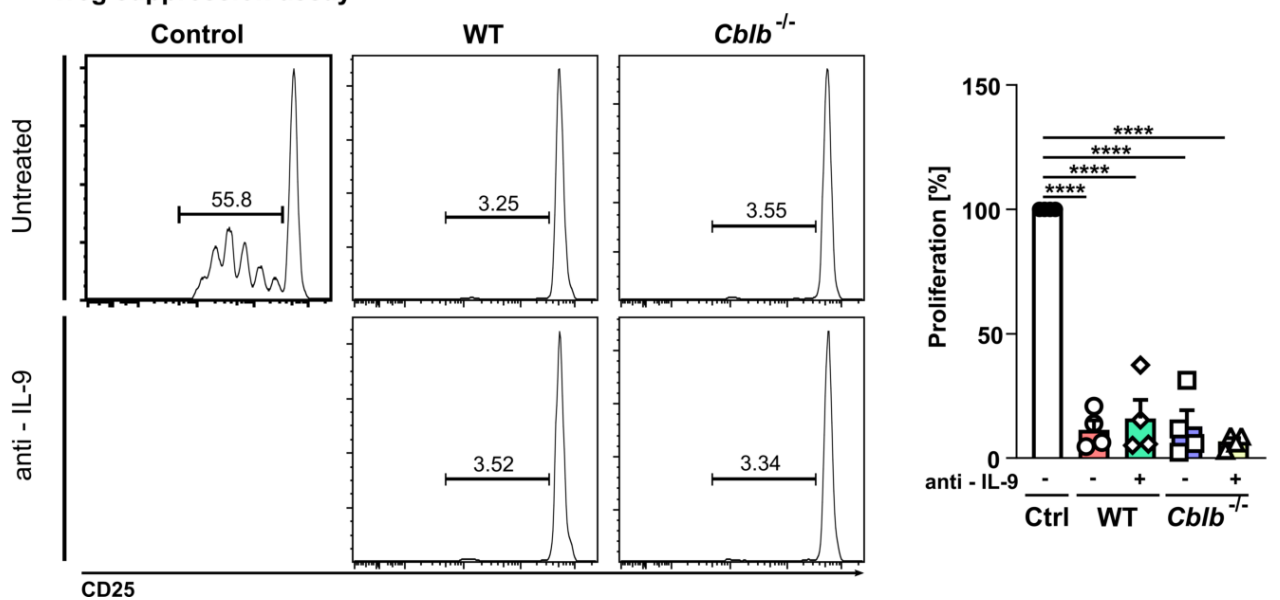

Figure 2 IL-9 supresses Treg differentiation but not Treg function in Cbl-b deficient naïve T cells. Naïve WT or Cblb ${ }^{-/-}$CD4 ${ }^{+}$ T cells were polarized to Treg cells by stimulation with plate-bound anti-CD3 antibodies, soluble anti-CD28 antibodies and a cytokine cocktail $(100 \mathrm{U} / \mathrm{mL}$ IL-2, $5 \mathrm{ng} / \mathrm{mL}$ hTGF $\beta)$. Additional anti-IL-9 blocking antibodies were added at concentrations of 5 , 10 or $20 \mu \mathrm{g} / \mathrm{mL}$. After 5 days in culture, cells were stained with fluorescently labeled antibodies and analyzed by flow cytometry. (A) Cells were pre-gated on CD45 ${ }^{+} D^{-}$cells. Frequency of Treg $\left(\mathrm{CD}^{2} 5^{+} \mathrm{Foxp} 3^{+}\right)$and $(\mathrm{B})$ mean fluorescent intensity (MFI) of Foxp3. (C) Exemplary histograms from analyzed WT and Cbl-b deficient Treg after 5 days of culture, showing expression of Foxp3 and CD25 in untreated control cells or after incubation with 5,10 or $20 \mu \mathrm{g} / \mathrm{mL}$ anti-IL-9 neutralizing antibody, respectively. (D) Naïve WT or Cbl-b deficient CD4 ${ }^{+}$T cells were polarized to Treg in the presence or absence of neutralizing anti-IL-9 $(20 \mu \mathrm{g} / \mathrm{mL})$. At day 5 Treg were sorted $\left(C D 4{ }^{+} C D 25^{\text {hi }} C D 45 R^{\text {lom }}\right)$ and co-cultured with CD3-depleted splenocytes and CFSE-stained CD4 ${ }^{+}$ conventional $T$ cells $\left(T_{\text {conv }}\right)$ at 1:1:1 ratio. Suppression of Tconv by Treg was measured by CFSE dilution after three more days of culture. (E) Evaluation of suppression by WT and $\mathrm{Cblb}^{-/-}$Treg. Data is pooled from at least two independent experiments and plotted as mean \pm SEM ( $n=4$ biological replicates). (C/D) Data is representatively taken from one of at least two independent experiments with at least $n=4$ biological replicates. Significance was calculated by two-way analysis of variance and multiple comparison test, corrected by Sidak post hoc analysis, as recommended by GraphPad Prism software $\left({ }^{*} \mathrm{p}<0.05,{ }^{* \star} \mathrm{p}<0.01\right.$, $\left.{ }^{* * \star} p<0.001,{ }^{* * * *} p<0.0001\right)$. Cbl-b, casitas B-lineage lymphoma proto-oncogene-b; CFSE, carboxyfluorescein succinimidyl ester; Foxp3, forkhead box P3; hTGF, human transforming growth factor; IL, interleukin; Treg, regulatory T cells; WT, wildtype. 
A

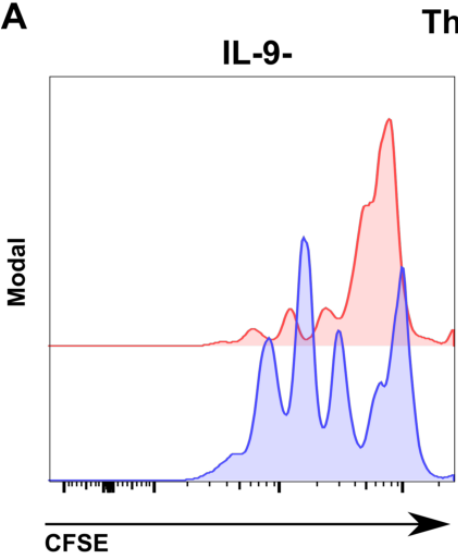

B

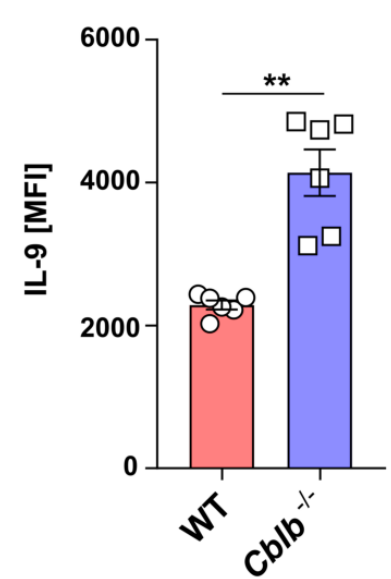

F

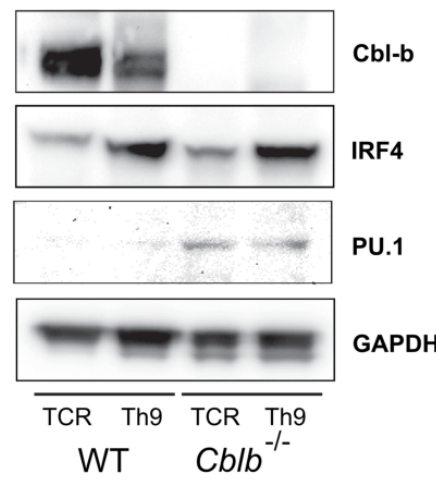

Th9

IL-9+

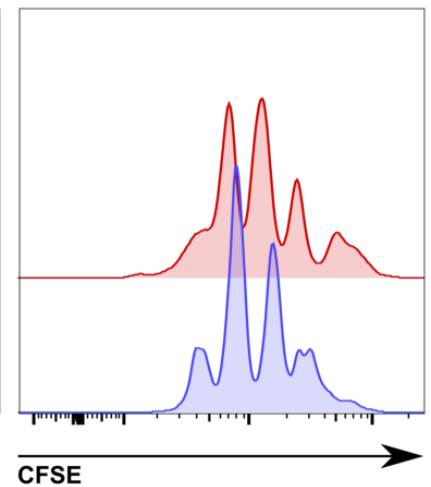

C

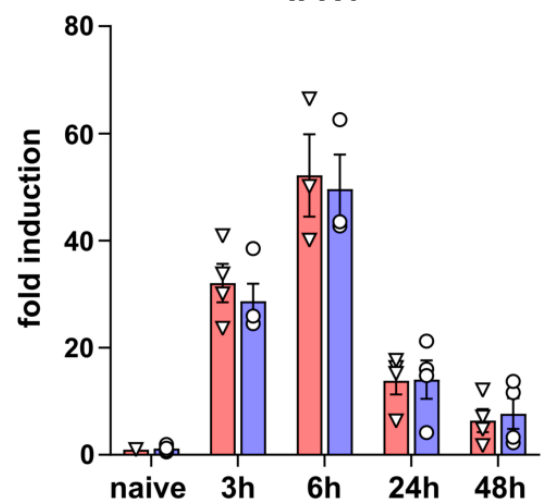

D

Treg

— WT

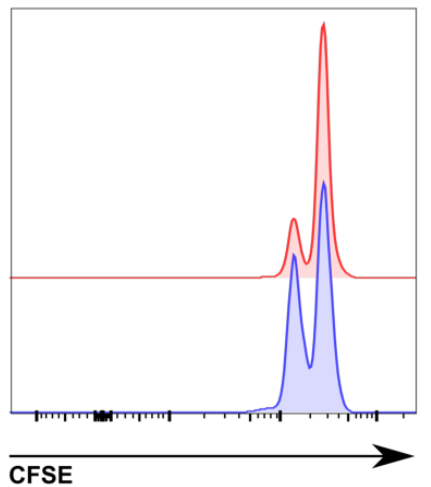

Foxp3- $-\mathrm{Cblb}^{-1 /}$

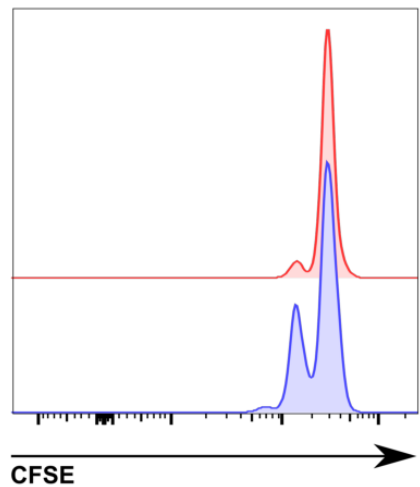

CFSE

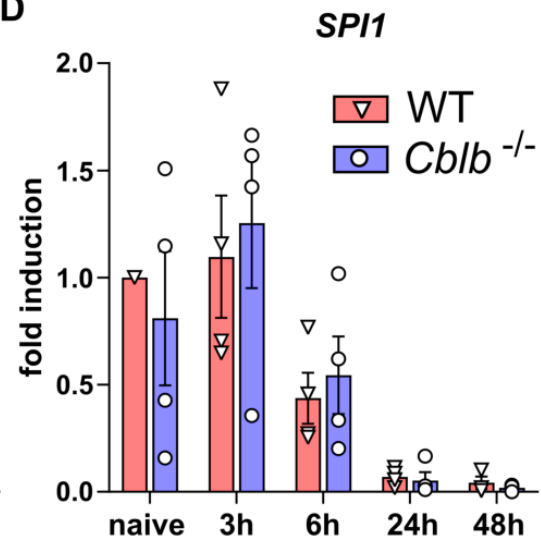

E
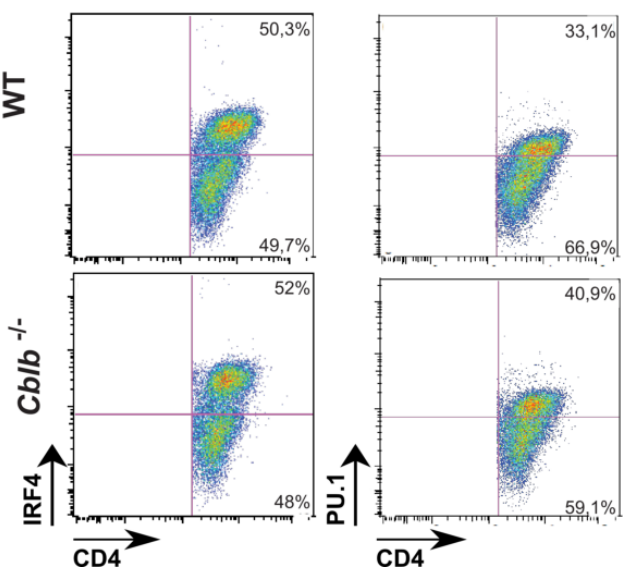

Figure 3 IRF4 and PU.1 expression is not altered in Cbl-b deficient Th9 cells. (A) WT and $\mathrm{Cb} \mathrm{b}^{-/-}$naïve T cells were stained using CFSE and differentiated for 3 days into Th9 cells or Treg. Viable cells were gated on IL-9 producing and non-producing $\mathrm{CD}^{+} \mathrm{T}$ cells or $\mathrm{CD}^{2} 5^{+} \mathrm{Foxp}^{+}$and $\mathrm{CD}_{2} 5^{+} \mathrm{Foxp}^{-}$cells, respectively. Representative histograms ( $\mathrm{n}=3$ biological replicates) of the relative proliferation of the two observed populations is shown. (B) Mean fluorescence intensity (MFI) of IL-9 from viable IL- $9^{+} T$ cells (mean \pm SEM, $n=6$ biological replicates) were graphically plotted. (C/D) RNA was isolated from naïve $C D 4^{+} T$ cells after 3, 6, 24 and 48 hours of Th9 cell culture. Complementary DNA was synthesized, and quantitative PCR was performed to quantify the expression of IRF4 and SPI1 by using the ddct method with GAPDH as housekeeping gene. (E) Naïve WT or Cbl-b deficient CD4 ${ }^{+} \mathrm{T}$ cells were polarized to Th9 cells for 72 hours and analyzed for expression of IRF4 and PU.1 proteins after intracellular staining by flow cytometry. (F) Western blot analysis of Cbl-b, IRF4 and PU.1 protein expression after 3 days of Th9 cells differentiation or sole TCR stimulation (CD3/28). Data for $(A)$ is representative taken from four independent experiments with at least four biological replicates and $(B)$ is pooled from four independent experiments and plotted as mean \pm SEM ( $n=6$ biological replicates). (C/D) Data is pooled from at least two independent experiments ( $n=4$ biological replicates). FACS plots in (E) are representative of two to three independent experiments and at least four biological replicates. $(F)$ is representative of at least two independent experiments and four biological replicates. Cbl-b. casitas B-lineage lymphoma proto-oncogene-b; CFSE, carboxyfluorescein succinimidyl ester; IL, interleukin; IRF4, interferon regulatory factor 4; TCR, T cell receptor; Treg, regulatory T cells; WT, wildtype. 
naïve T cells and after 3 hours of Th9 cell differentiation but declined over time (figure 3D). However, no significant differences were observed between WT and $\mathrm{Cblb}^{-1}$ cells. We also investigated IRF4 and PU.1 protein levels through flow cytometry (FACS) and western blot (WB) analysis. While IRF4 was clearly detectable but equally expressed in WT and $\mathrm{Cblb}^{-1-}$ Th9 cells, PU.1 was not as strongly expressed and was consequently barely detectable by FACS and WB analysis (figure 3E,F). Nonetheless, the frequency of PU. $1^{+}$cells (figure $3 \mathrm{E}$ ) and PU.1 protein levels (figure 3F) seemed to be slightly higher in $\mathrm{Cblb}^{-1-}$ Th9 cells, although this effect was not statistical significant. Because the results obtained for PU.1, especially the detection by WB, did not wholly satisfy us and might even be inadequate to explain the big differences in Th9 cell differentiation, we opted for a broader omics-based analysis at the single-cell level to better understand the observed changes during in vitro Th9 cell differentiation.

\section{Single-cell RNA sequencing of in vitro generated Th9 cells}

To understand the differences between WT and $\mathrm{Cblb}^{-1-}$ Th9 cells we performed a microarray and proteomic analyses of in vitro differentiated Th9 cells (data not shown). However, by virtue of these techniques, not discriminating between IL-9 ${ }^{+}$and other cells in the culture, we could not identify candidates that could potentially explain the phenotype of $\mathrm{Cblb}^{-/-} \mathrm{Th} 9$ cells, presumably due to the relatively low frequency of IL-9 positive cells in the culture and the technique-inherent limitation of providing only integrals of protein and mRNA expression levels. Therefore, we performed single-cell mRNA sequencing $(45,000$ cells with a depth of 80,000 reads per cell) of in vitro differentiated Th9 cells in order to deconvolute the cellular complexity of Th9 cell cultures (figure 4A).

The global volcano plot depicts genes with the highest $\log _{2}$ fold change (FC) values and highlights that $I l 13, I l 9$, Gatm, Gm10093 and Lgals1 had the highest upregulation in $\mathrm{Cblb}^{-/-}$compared with WT Th9 cells (online supplemental figure 5B). After 48 hours of Th9 cell differentiation, graph-based clustering led to the formation of six major and one minor clusters shown in two-dimensional t-distributed stochastic neighbor embedding (tSNE) space. All seven clusters were equally found in the WT and $\mathrm{Cblb}^{-/-}$Th9 cultures (figure $4 \mathrm{~B}$ and online supplemental figure 5A). Hence, knocking out Cbl-b shifts the frequency of the diverse subsets rather than generating novel $\mathrm{T}$ cell populations, with clusters 0 and 2 growing and clusters 1 and 3 shrinking in $\mathrm{Cblb}^{-/-}$cultures (figure 4C). The calculated cluster identities corresponded well to the two-dimensional representation in tSNE and Uniform Manifold Approximation and Projection space (online supplemental figure 5A). The six major and one minor clusters express an array of marker genes, including cluster 2, which showed the highest level of $I l 9$ expression and were allocated as Th9 cells (figure 4D). This cluster was about three times larger in cultures from $\mathrm{Cblb}^{-/-}$mice than WT mice, which is in line with the FACS analysis of
Th9 cultures shown in figure 1 (figure 4B,C). Besides $I l 9$, cluster 2 showed high expression of Batf 3 , Lta, and Vim, all of which have previously been connected to Th9 cell biology. ${ }^{55}$ In order to understand what distinguishes the cluster 2 Th9 cells in WT vs $\mathrm{Cblb}^{-/-}$cultures (besides sheer cluster size), we investigated differentially expressed genes (DEGs), with a particular look at the top 100 genes with the highest expression differences $\left(\log _{2}\right.$ FC). Beyond the genes with the highest significant upregulation in $\mathrm{Cblb}^{-/-}$cells compared with WT cells, we identified Il13, Satb1, Cd53, Ntrk3, Ctla4, and others (figure $4 \mathrm{E}, \mathrm{F}$ ). The genes with the highest downregulation in $\mathrm{Cblb}^{-/-}$cluster 2 cells are, for example, the unclassified genes Gm42031, Gm47283 and Ccl4, Irf8, or Coro2a. Gene Ontology (GO) analysis of all cluster 2 DEGs $\left(\mathrm{P}_{\text {adj }}\right.$ $<0.05)$ revealed that the genes were most significantly enriched for the Biological Processes 'T cell activation', 'JAK-STAT cascade', and 'positive regulation of cytokine production' (figure 4G). Highly enriched molecular functions were 'cytokine receptor binding' and 'receptor regulatory activity', enriched cellular components (CCs) are 'mitochondrial outer membrane', 'external side of plasma membrane' and 'outer membrane'. In addition to GO analysis, we also looked at Enriched Kyoto Encyclopedia of Genes and Genomes (KEGG) pathways. The most highly upregulated pathways are the 'JAK-STAT signaling pathway', 'Cytokine-cytokine receptor interaction' and 'TNF signaling pathway' (figure $4 \mathrm{H}$ ). Finally, we confirmed that Cbl-b and IL-9 were reversely regulated (online supplemental figure 6E). Similar Cblb expression levels were observed in all major clusters except for IL-9 positive cluster 2 (online supplemental figure $6 \mathrm{~B}, \mathrm{D}$ ). The latter exhibited significantly lower $C b l b$ expression levels than the remaining cell clusters (online supplemental figure $6 \mathrm{~B}, \mathrm{C}, \mathrm{F})$.

Taken together, the sequencing approach revealed that high Cblb expression limits the polarization of Th9 cells by limiting $I l 9$ expression. Consequently, deficiency for Cblb in naive T cells favors Th9 cell polarization and leads to the generation of Th9 cells that show a different gene expression profile and upregulation of pathways associated with $\mathrm{T}$ cell activation or cytokine stimulation. Therefore, we next wondered if $\mathrm{Cblb}^{-/-}$Th9 cells might also be functionally different from WT Th9 cells.

\section{Adoptively transferred $\mathrm{Cblb}^{-/-}$Th9 cells exert superior antitumor activity}

Based on our in vitro results, we next investigated whether increased differentiation of Th9 cells from $\mathrm{Cblb}^{-/-}$versus WT naïve T cells affected their ability to influence tumor growth. As a tumor-antigen cancer model, we crossed OT-II mice with $\mathrm{Cblb}^{-/-}$mice to generate OVA-specific $\mathrm{Cblb}^{-/-}$Th9 cells and injected C57BL/6 mice with the B16F10-OVA melanoma cell line. At days 5 and 10 of the tumor experiments, $3 \times 10^{\wedge} 6$ in vitro differentiated OT-II Th9 cells or OT-II* $\mathrm{Cblb}^{-/-}$Th9 cells were intravenously injected into the tumor-bearing mice (figure $5 \mathrm{C}$ ). Similar to WT and $\mathrm{Cblb}^{-1-}$ Th9 cells, naïve OT-II T cells 
A

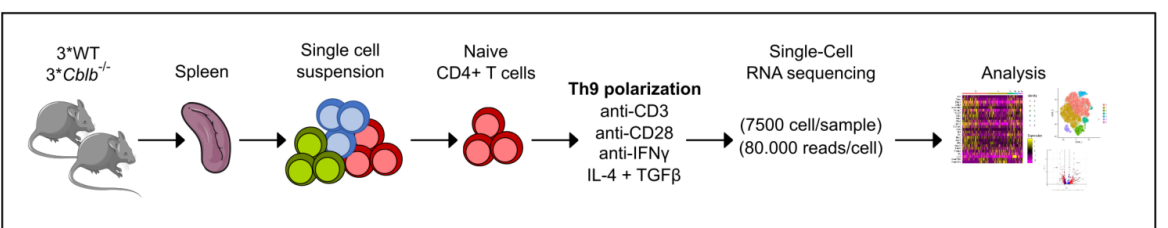

B

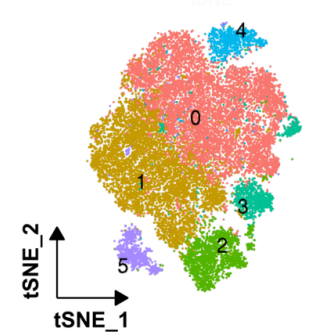

E Cluster 2 Heat Map (TOP100 DEGs)

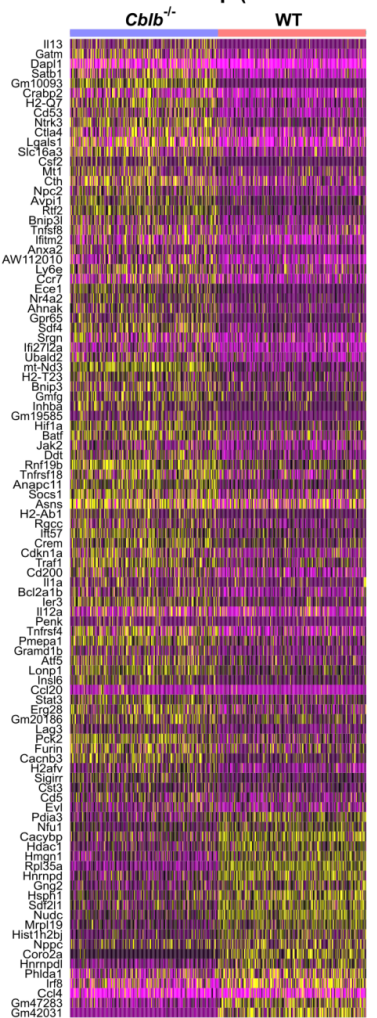

tSNE

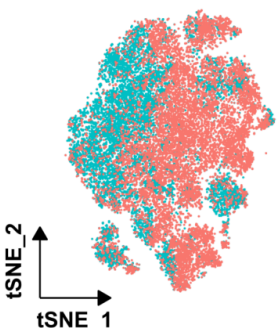

F

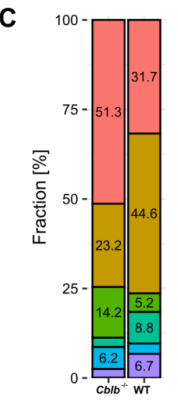

Cluster 2 Volcano Plot

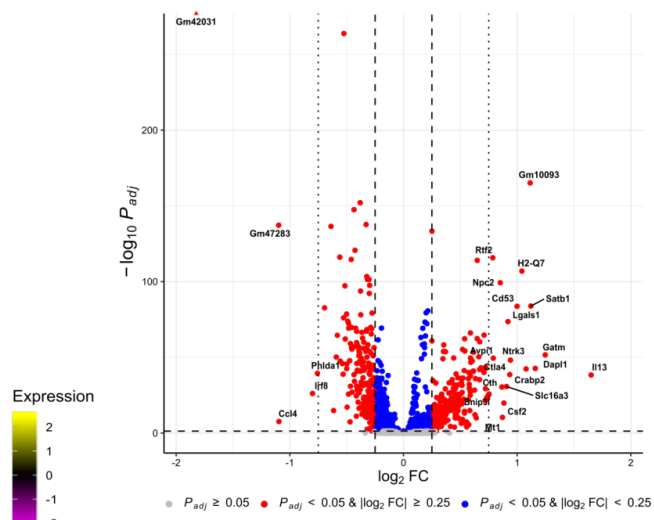

D Top 5 cluster

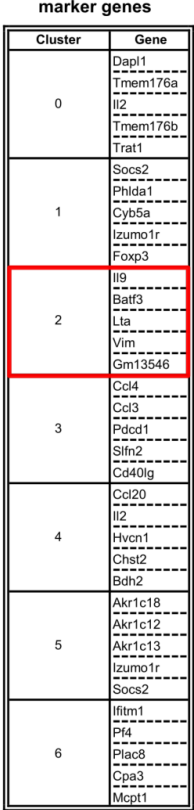

G Enriched Gene Ontology Terms of cluster 2 Biological Process

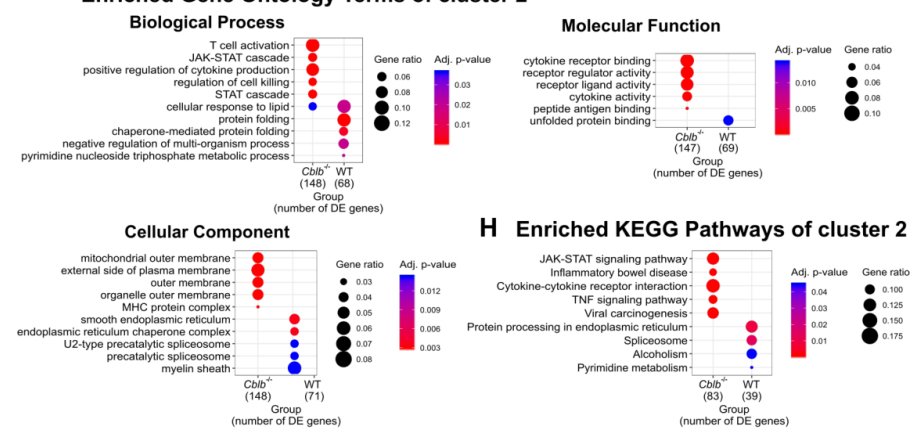

Figure 4 Single-cell RNA sequencing of in vitro differentiated Th 9 cells. (A) Naïve CD4 ${ }^{+}$T cells were isolated from murine splenocytes (six biological replicates, $3 \times \mathrm{WT}$ and $3 \times \mathrm{Cblb}^{-1-}$ mice) and cultured for 48 hours under Th9 polarizing. Subsequent single-cell RNA sequencing was performed on 7500 cells per sample and at a depth of approximately 80,000 reads/cell. (B) Graph-based clustering led to formation of six major and one minor clusters, which are shown in two-dimensional t-distributed stochastic neighbor embedding (tSNE) space. (C) Distribution of cells across the six major clusters. (D) Top five marker genes ranked by fold change per cluster. (E) Expression heatmap of the top 100 differentially expressed genes (DEGs) of cluster 2 sorted by foldchange (KO vs WT). (F) Volcano plot depicting differentially expressed genes in Cb/b ${ }^{-/-}$CD4 ${ }^{+} \mathrm{T}$ cells of cluster 2 . Gray dots represent genes with non-significant difference in expression between $\mathrm{Cbl}_{-} \mathrm{b}^{-/-}$and WT cells $\left(\mathrm{P}_{\mathrm{adj}} \geq 0.05\right)$. Red dots represent genes with $P_{\text {adj }}<0.05$ and $\left|\log _{2} F C\right| \geq 0.25$ while blue dots represent genes with $P_{\text {adj }} \mid 0.05$ and $\left|\log _{2} F C\right|<0.25$. Gene names are shown for differentially expressed genes with $P_{\text {adj }}<0.05$ and $\left|\log _{2} F C\right| \geq 0.75$. Data points with $p$ value below the technical representation limit are displayed as triangles. Y-axis denotes '-log10 $P_{\text {adj }}$ 'values while X-axis shows 'log ${ }_{2} F C$ ' values. (G) Gene ontology (GO) enrichment analysis of genes with differential expression between $\mathrm{Cb}^{-/ /} \mathrm{b}^{-/}$and WT cells of cluster 2. Enriched gene ontology terms are shown from the categories biological process, cellular component and molecular function. (H) KEGG pathways enriched in $\mathrm{Cb}_{\mathrm{l}} \mathrm{b}^{-/-}$or WT cells of cluster 2, ranked by adjusted $\mathrm{p}$ values are depicted. $(\mathrm{G} / \mathrm{H}) \mathrm{The}$ gene ratio corresponds to the number of DE genes annotated with a specific term divided by the total number of DE genes. The dot size visualizes the absolute count of DE genes annotated with a term; dot color encodes the adjusted $p$ value. Adj., adjusted; Cbl-b, casitas B-lineage lymphoma proto-oncogene-b; DE, differentially expressed; FC, fold change; IFN, interferon; KEGG, Kyoto Encyclopaedia of Genes and Genomes; KO, knock-out; TGF, transforming WT, wild type. 
A

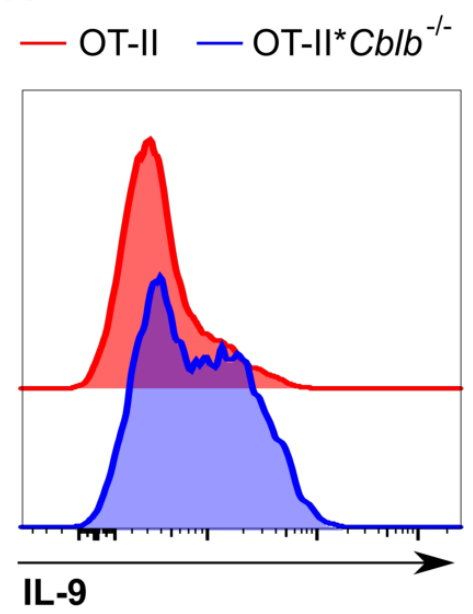

B

D OT-II 0 OT-II*Cb/b ${ }^{-1-}$
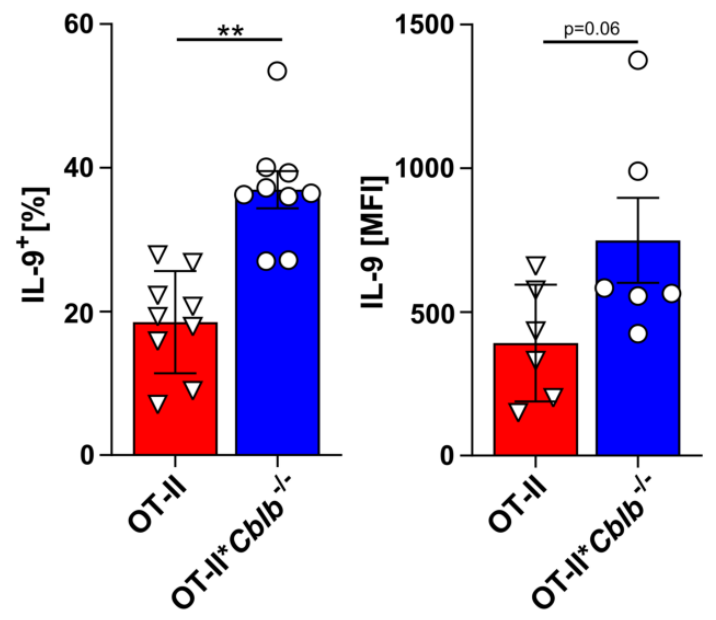

C

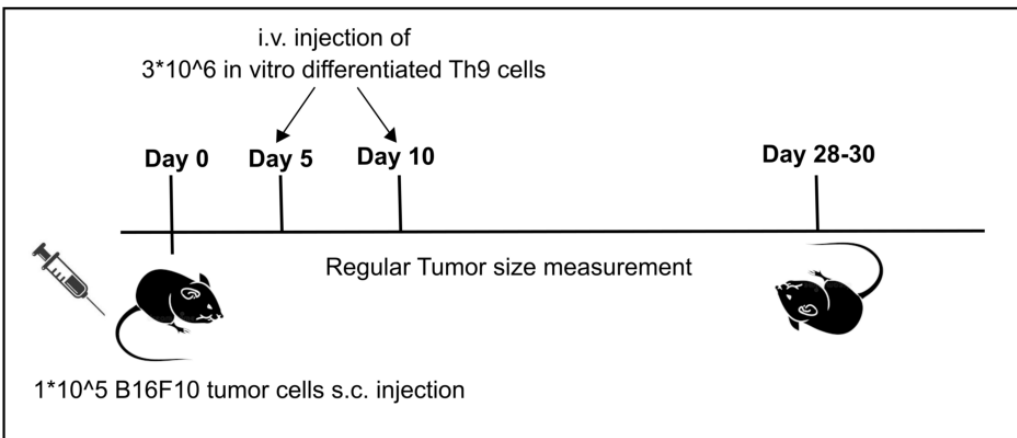

D

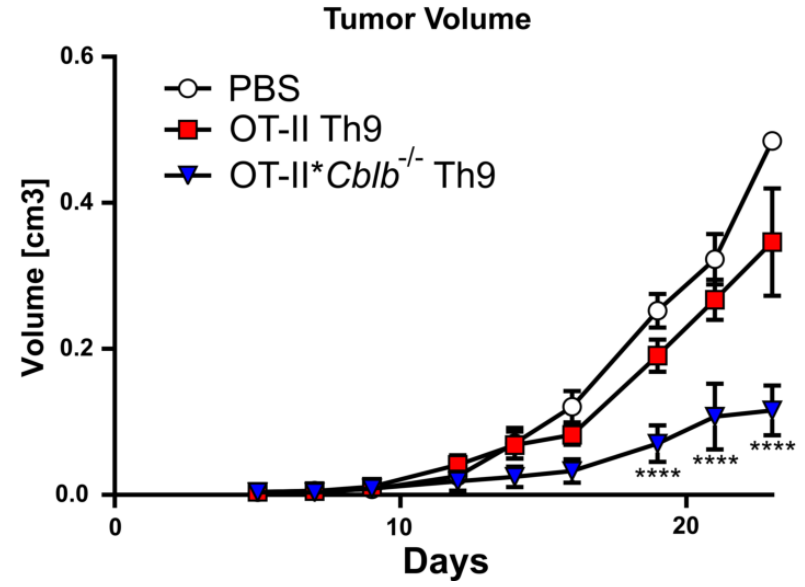

E

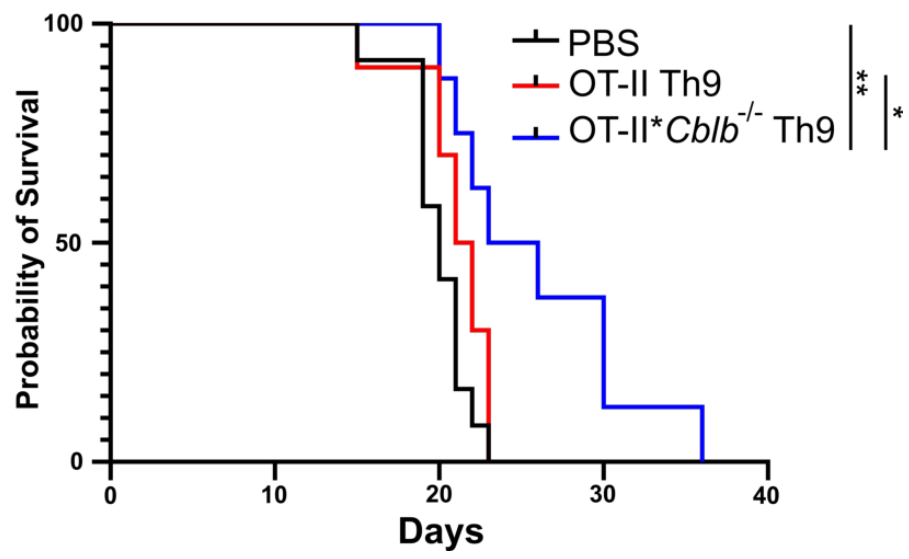

Figure 5 In vitro generated $\mathrm{Cb}_{1} b^{-/-}$Th9 cells delay B16-OVA tumor growth in WT mice. Naïve (CD4 $\left.{ }^{+} \mathrm{CD} 62 \mathrm{~L}^{+} \mathrm{CD} 44^{-}\right) \mathrm{T}$ cells carrying the OT-II T cell receptor (OT-II) or the OT-II T cell receptor and additional deficiency for Cbl-b (OT-II* $C b /-b^{-/-}$) were differentiated for 48 hours under Th9 polarizing conditions. (A) Representative plots (at least three independent experiments) of intracellular IL-9 staining of OT-II and OT-II*Cblb ${ }^{-/-}$Th9 cells used for adoptive transfer experiments. (B) Frequency of IL-9 positive cells after 48 hours of differentiation and IL-9 MFI of in vitro differentiated Th9 cells. Data is pooled from three independent experiments ( $n=6$ biological replicates) and significance is determined by unpaired t-test. (C) Schematic representation of the experimental procedure. C57BL/6 mice are subcutaneously (s.c.) injected with $1 \times 10^{\wedge} 5 \mathrm{~B} 16 \mathrm{~F} 10-\mathrm{OVA}$ melanoma cells at day 0 . At days 5 and $103 \times 10^{\wedge} 6$ OT-II Th9 cells or OT-II*Cblb ${ }^{-1-}$ Th9 cells are adoptively transferred into tumor bearing mice. Tumor growth (D) and survival (E) of mice in different experimental groups was closely monitored. Length, width and height of each tumor was measured by using a caliper and tumor volume was calculated by using the following formula: length $\times$ wide $\times$ height $\times \pi / 6$. Data is pooled from at least two independent experiments (mean $\pm S E M)(n=8-12$ mice). Significance is calculated by two-way analysis of variance, corrected by Sidak post hoc analysis (D), and Mantel-Cox test (E) $\left({ }^{*} \mathrm{p}<0.05\right.$, $\left.{ }^{* \star} \mathrm{p}<0.01,{ }^{* \star *} \mathrm{p}<0.001,{ }^{* \star \star \star} \mathrm{p}<0.0001\right)$. Cbl-b, casitas B-lineage lymphoma proto-oncogene-b; IL, interleukin; i.v., intravenous; MFI, mean fluorescence intensity; WT, wildtype. 
generated from a $\mathrm{Cblb}^{-/-}$background exhibited improved Th9 cell differentiation (when compared with WT OT-II Th9 cells), as evaluated by intracellular staining for IL-9 and subsequent flow cytometry analysis (figure 5A/B; after 48 hours of Th9 cell polarization, frequency of IL- $9^{+}$ cells was almost doubled with $20 \%$ in OT-II Th9 cells vs $40 \%$ in OT-II* $\mathrm{Cblb}^{-/-}$Th9 cells). Injection of WT OT-II Th9 cells slightly decreased tumor growth (at least in this dosing schedule) but did not prolong the survival of tumor-bearing mice (figure 5D,E). In contrast, Th9 cells generated from OT-II* $\mathrm{Cblb}^{-/-}$mice showed significantly inhibited tumor growth when compared with the group that received WT OT-II Th9 cells (figure 5D). In line with their increased antitumor reactivity, mice receiving OT-II* $\mathrm{Cblb}^{-/-}$Th9 cells had significantly improved survival compared with mice that received Cblb-proficient OT-II Th9 cells (figure 5E). In order to understand whether Th9 cells directly kill B16 tumor cells or if the effect is indirect through other immune cells, we co-cultured in vitro generated Th9 cells with a 1:1 mixture of B16-WT and B16-OVA tumor cells, labeled with different concentrations of CFSE. Using this approach, we could not detect any significant difference in the killing activities of either OT-II Th9 or OT-II* $\mathrm{Cblb}^{-1-}$ Th9 cells against B16-WT or B16-OVA cells (online supplemental figure 7), which indicates an indirect effect rather than direct tumor cell killing. Our data show that $\mathrm{Cblb}^{-/-}$Th9 cells, in contrast to WT Th9 cells, can delay melanoma growth, presumably by acting on other immune cells. However, the exact role of IL-9 in this context remains unclear. Therefore, we next defined the role of IL-9 in the tumor rejection phenotype of $\mathrm{Cblb}^{-/-}$animals.

\section{IL-9 is critically involved in tumor-rejection in $\mathrm{Cblb}^{-/-}$mice}

$\mathrm{Cblb}^{-/-}$mice spontaneously reject tumors, an observation mainly attributed to tumor-specific $\mathrm{CD} 8^{+} \mathrm{T}$ cells that are resistant to Treg-mediated suppression. ${ }^{39}$ Our data now highlight that in addition to $\mathrm{CD} 8^{+} \mathrm{T}$ cells, Th9 cells and, more specifically, IL-9 are involved in this tumor rejection phenotype. Therefore, we subcutaneously injected either WT or $\mathrm{Cblb}^{-1-}$ mice with the melanoma cell line HCmel3 and measured $I l 9 \mathrm{mRNA}$ expression in the tumor tissue by quantitative PCR (qPCR) at day $30 .{ }^{43} \mathrm{Cblb}^{-1-}$ mice showed significantly higher $I l 9$ expression levels in the tumor tissue in vivo, further suggesting a potential role for IL-9 in suppressing tumor growth in $\mathrm{Cblb}^{-/-}$mice (figure 6A). In order to confirm this hypothesis, we treated HCmel3 injected $\mathrm{Cblb}^{-1-}$ mice intravenously on days $-1,0,1$ and every following third day with a neutralizing anti-IL-9 antibody (figure 6B). As expected, ${ }^{39} \mathrm{Cblb}^{-/-}$mice injected with control IgG showed significantly decreased tumor growth (figure 6C) and smaller tumors (figure 6D,E). In contrast, blocking IL-9 re-established cancer growth, even though WT mice still had the most extensive tumors, indicating that IL-9-independent pathways are also involved in cancer growth suppression in $\mathrm{Cblb}^{-1-}$ animals (figure 6C-E). To understand differences in general tissue layout of the tumors in WT, $\mathrm{Cblb}^{-1-}$, and anti-IL-9 treated $\mathrm{Cblb}^{-/-}$mice, we performed a H\&E stain and CD45 staining to visualize the tumor infiltrating leukocytes (figure 6F). While we observed big tumors with typical melanoma appearance in WT mice, in $\mathrm{Cblb}^{-/-}$mice tumors were eradicated to a high degree and hence structurally different. Despite being not as small, tumors in anti-IL-9 treated $\mathrm{Cblb}^{-/}$ mice structurally resembled tumors in $\mathrm{Cblb}^{-/-}$mice. CD45 staining revealed a low degree of immune cell infiltrate in tumors of WT mice, while a high degree of CD45 expression in tumors of $\mathrm{Cblb}^{-1-}$ mice indicated a high degree of immune cells infiltration at this time point. CD45 expression in anti-IL-9 treated $\mathrm{Cblb}^{-/-}$mice were intermediate.

Next, to characterize these infiltrates in more detail, we isolated tumor-infiltrating lymphocytes (TILs) and mapped their composition by flow cytometry (figure 6G). While there could not be observed any differences for the overall frequency of $\mathrm{CD} 45^{+}$immune cells infiltrating the tumors by FACS, the frequency of T cells was significantly higher in tumors isolated from $\mathrm{Cblb}^{-/-}$mice compared with the one from WT mice (figure 6G). In-depth analysis of the infiltrating $\mathrm{T}$ cells revealed a higher $\mathrm{CD}^{+} /$ $\mathrm{CD}^{-} \mathrm{Foxp}^{+}$ratio and a lower $\mathrm{CD} 4^{+} / \mathrm{CD}^{+}$ratio in $\mathrm{Cblb}^{-/-}$ mice than in WT mice, indicating the dominance of CD8 ${ }^{+}$ $\mathrm{T}$ cells over Treg $\left(\right.$ Foxp $\left.^{+}\right)$and $\mathrm{CD} 4^{+} \mathrm{T}$ cells within all $\mathrm{CD}^{+} \mathrm{T}$ cells (figure 6G). Blocking of IL-9 led to a partial reversal of these effects, lowering the $\mathrm{CD}^{+} / \mathrm{CD}^{-} \mathrm{Foxp}^{+}$ ratio and increasing the $\mathrm{CD} 4^{+} / \mathrm{CD}^{+}$ratio, indicating an involvement of IL-9 in regulating the composition of T cell subsets by modulating the frequency of specific $\mathrm{T}$ cell subsets such as $\mathrm{CD}^{+} \mathrm{T}$ cells. Taken together, these data confirm the in vitro observation that knocking out Cbl-b leads to an increased expression of IL-9 in the tumor microenvironment and that IL-9 is at least partly responsible for the tumor rejection phenotype of $\mathrm{Cblb}^{-/-}$mice.

\section{DISCUSSION}

Cbl-b is an intracellular immune checkpoint that negatively regulates receptor tyrosine kinase signaling, thereby limiting the antitumor reactivity of $\mathrm{T}$ and NK cells. ${ }^{35-39} 46$ Accordingly, the lack of $C b l b$ in immune cells boosts their ability to eradicate solid tumors involving $\mathrm{CD} 8^{+} \mathrm{T}$ and NK cells. ${ }^{39} 414748 \mathrm{Cbl}-\mathrm{b}$ also regulates T helper cell polarization. ${ }^{42}{ }^{49}$ Cblb is highly expressed in $\mathrm{CD} 4^{+}$and $\mathrm{CD} 8^{+} \mathrm{T}$ cells, and its expression is tightly regulated by co-stimulatory and inhibitory molecules. ${ }^{31}{ }^{32}$ The starting point of our study was the considerably lower expression of $\mathrm{Cblb}$ in Th9 cells than in Th0 and Treg cells. Hence, we speculated that besides the well-documented roles of Cbl-b in the regulation of $\mathrm{T}$ cell activation, there might be a more specific role for Cbl-b in Th9 cell differentiation. ${ }^{50} 51$ The lack of generally stronger $\mathrm{T}$ cell activation signals in $\mathrm{Cblb}^{-/-}$Th9 cells (ie, NFAT upregulation or increased nuclear entry) further supports this assumption. We showed that Th9 differentiation was more quickly and efficiently initiated in the absence of Cbl-b. However, this process is not dependent on deregulation of the known Th9 transcription factors PU.1 and IRF4. ${ }^{34}$ Despite the 


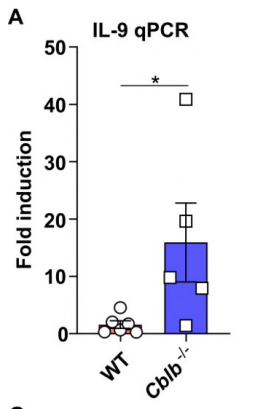

C

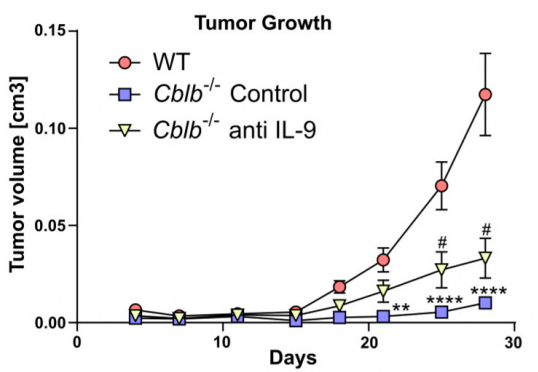

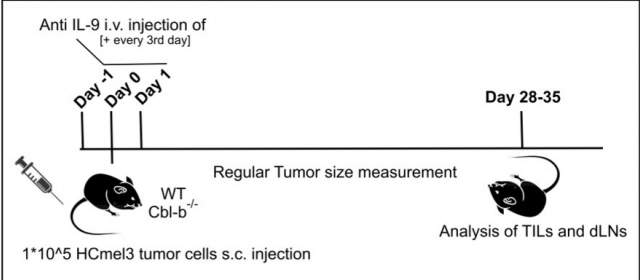

D

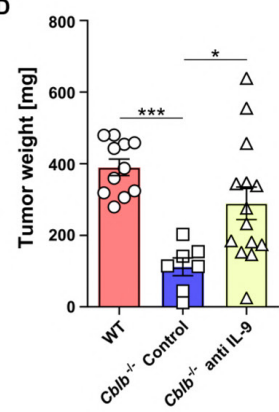

$\square$ WT

띠 $\mathrm{Cb}^{-/-}$Control

$\square \mathrm{Cblb}^{-1-}$ anti IL-9

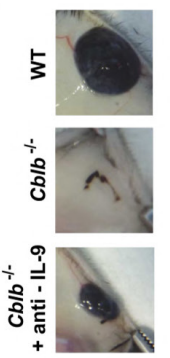

$\mathbf{F}$

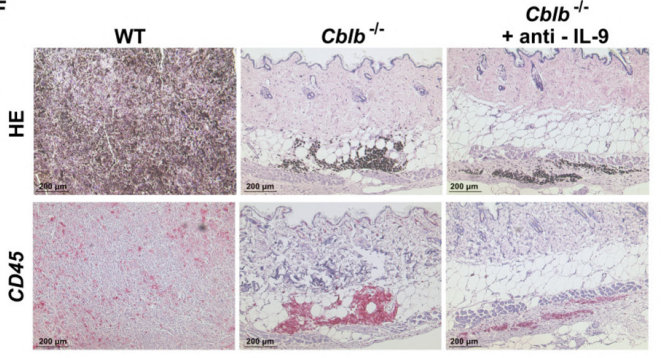

G
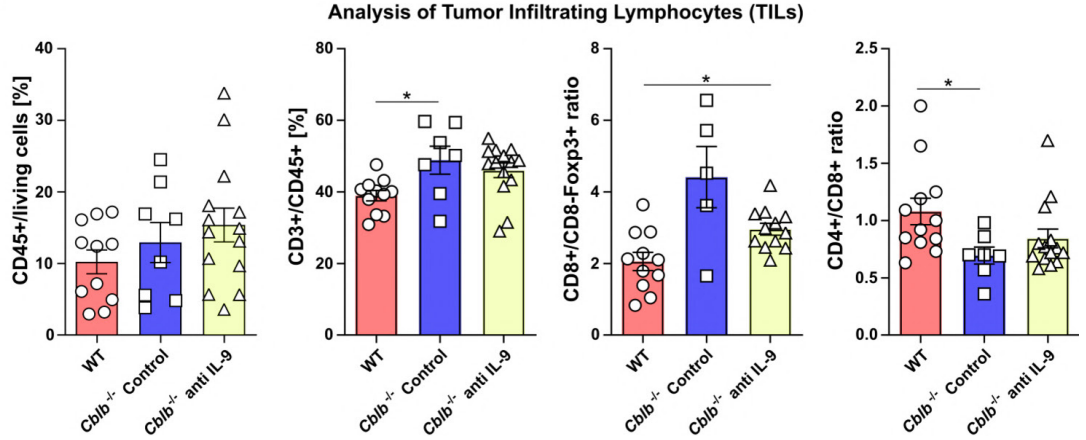

Figure 6 Repression of tumor growth in $\mathrm{Cblb}^{-/-}$mice depends partly on IL-9 (A) WT and Cblb $b^{-/-}$mice were injected s.c. with $1 \times 10^{\wedge} 5 \mathrm{HCmel} 3$ tumor cells. Tumors were extracted at day 30 , RNA was isolated, transcribed into complementary DNA and quantitative PCR for IL-9 was performed using the ddct method and GAPDH as housekeeping gene. (B) Schematic representation of experimental procedure. WT and $\mathrm{Cb} \mathrm{b}^{-/-}$mice are intraperitoneally injected with $100-200 \mu \mathrm{g} / \mathrm{mL}$ anti-IL-9/ IgG kappa antibodies for three consecutive days, starting from a day (day -1) prior to subcutaneous injection of $\mathrm{HCmel} 3$ tumor cells (day 0). Subsequently the mice are injected with anti-IL-9/IgG kappa antibodies every third day until they are sacrificed. (C) Tumor growth of mice in different experimental groups was closely monitored. Length, width and height of each tumor were measured using a caliper and tumor volume was calculated by using the following formula: length $\times$ widexheight $\times \pi / 6$. (D) Tumors were extracted and weighed between days 28 and 35 or when termination criteria where reached. (E) Exemplary photos of $\mathrm{HCmel} 3$ tumors at day 30 are shown. (F) Tumor samples were immersed in a zinc-based fixative (BD Pharmingen), embedded in paraffin and stained with H\&E according to standard protocols. Immunohistochemistry was performed with rat anti-mouse CD45 mAb (30-F11) from BD Pharmingen. Representative pictures from the respective groups are shown. (G) Tumor infiltrating lymphocytes (TILs) were isolated and stained with fluorescently labeled antibodies and analyzed by FACS. T cells were quantified as percentage of all $\mathrm{CD} 45^{+}$cells. The ratio between $\mathrm{CD} 8^{+} \mathrm{T}$ cells and $\mathrm{CD} 4^{+} \mathrm{T}_{\text {reg }}$ was calculated $\left(\mathrm{CD} 8^{+} / \mathrm{CD} 3^{+}\right.$ (\%) divided by $\left.\mathrm{CD}^{-} \mathrm{Foxp3}^{+} / \mathrm{CD3}^{+}(\%)\right)$. $\mathrm{CD}^{+} / \mathrm{CD}^{+}$ratio was calculated $\left(\mathrm{CD4}^{+} / \mathrm{CD}^{+}(\%)\right.$ divided by $\left.\mathrm{CD}^{+} / \mathrm{CD}^{+}(\%)\right)$. Data is representative for at least four independent experiments with (A) $n=5-6$ mice, (C) $n=25-30$ mice, (D) $n=5-14$ mice and (F) $n=5-14$ mice. Significance is calculated by unpaired t-test $(A)$ or ordinary one-way analysis of variance $\left({ }^{\star} p<0.05,{ }^{\star \star} p<0.01,{ }^{\star \star \star} p<0.001\right.$, ${ }^{* \star \star \star} p<0.0001$ ). Cbl-b, casitas B-lineage lymphoma proto-oncogene-b; IL, interleukin; i.v., intravenous; s.c., subcutaneous; WT, wildtype. 
hyperproliferation of T cells in the absence of Cbl-b, ${ }^{36}$ we show that hyper-proliferation is mainly seen in IL- $9^{-}$cells, which does not explain increased IL- $9^{+}$cell frequency. We propose that induction of $B A T F 3$, an activator protein 1 family transcription factor with high homology to BATF, drives increased Th9 differentiation, as it has recently been described to induce IL-9 expression. ${ }^{5}$ Using scRNA sequencing and qPCR validation, we identified $B A T F 3$ as one of the most prominently upregulated genes in $\mathrm{Cblb}^{-/-}$ versus WT IL-9 $9^{+}$cells. In broader terms, $\mathrm{Cblb}^{-/}$IL-9 ${ }^{+}$cells were highly enriched for GO terms like 'T cell activation', 'positive regulation of cytokine production' and 'regulation of cell killing', highlighting that these cells show a different transcriptional profile and might therefore be functionally different.

The initial $\mathrm{T}$ cell differentiation data and integration of the scRNA sequencing results suggest that increased Th9 differentiation is clearly paralleled by reduced Treg abundance. In-depth analysis of our scRNA sequencing data revealed a negative correlation between $C b l b$ and $I l 9$ expression at the per cell level, strengthening our hypothesis that Cbl-b might have a role in limiting $I l 9$ expression. Functionally, blocking IL-9 in $\mathrm{Cblb}^{-/-}$Treg cultures re-established proper Treg cell differentiation, suggesting that high concentrations of IL-9 in trans inhibit Treg differentiation. However, a direct function of IL-9 in inhibiting Treg differentiation is yet to be described, particularly as IL-9 has recently been shown to potentiate Treg function by activating STAT3/STAT5 and influencing the Th17/ Treg balance. ${ }^{52}$

In addition to its role in promoting IL-9 production and Th9 cell polarization, BATF3 has been shown to inhibit Treg differentiation by acting as a transcriptional suppressor of the Foxp3 locus. ${ }^{53}$ It has also been shown that OX40 signaling induces $B A T F 3$, hence inhibiting Foxp3 expression, and also induces Th9 cell differentiation, which has been proposed to be regulated by the non-canonical NF- $\mathrm{KB}$ pathway but could also involve BATF3. ${ }^{51253}$ OX40, a member of the TNFR superfamily of receptors, forms a signaling complex with TNF receptorassociated factor 2, protein kinase $\mathrm{B}$, and phosphoinositide 3-kinase (PI3K) and functions as a co-stimulatory signal to enhance the TCR signal. ${ }^{54} \mathrm{Cbl-b}$ has been shown to regulate the $\mathrm{p} 85$ subunit of PI3K negatively. ${ }^{55}$ Increased recruitment of $\mathrm{p} 85$ to $\mathrm{CD} 28$ increases $\mathrm{T}$ cell activation in $\mathrm{Cblb}^{-/-} \mathrm{T}$ cells. ${ }^{35}{ }^{36}$ Similarly, p85 could enhance OX40 signaling in absence of Cbl-b, inducing the expression of $B A T F 3$ and thus acting as a switch in balancing differentiation between Th9 and Treg cells. Besides OX40, other TNF family members, such as TNF $\alpha$, TL1A, and GITRL, have been shown to promote the induction of Th9 cells. ${ }^{9}$ We could show that under all $\mathrm{T}$ helper cell polarization conditions, $\mathrm{Cblb}^{-/-}$cells released more TNF $\alpha$ and that in addition 'TNF signaling pathway' was one of the most enriched KEGG pathways of cluster 2 in our scRNA sequencing approach.

Several previous reports have highlighted the strong and effective antitumor capacity of Th9 cells and IL- $9 .{ }^{56}$ Some data suggest that Th9 cells might be more potent in inhibiting cancer than Th1, Th2, or Th17 cells. ${ }^{57}$ IL-9 and the Th9 cell-derived cytokine IL-21 can enhance mast cell activation, promote the recruitment of dendritic cells, and support cytolytic functions of CTLs and NK cells. Of note, IL-9 can also exert a tumorigenic role in hematological tumors, acting as a lymphocyte growth factor and in solid tumors, promote proliferation and migration of cancer cells. ${ }^{22} 5859$ Our data suggest that under physiological conditions Cbl-b limits the differentiation of Th9 cells. Hence, targeting Cbl-b pharmacologically or genetically might represent an attractive way to boost antitumor immunity. According to this idea, in vitro differentiated OT-II* $\mathrm{Cbl}^{-/-}$Th9 cells exert significantly more potent anti-cancer effects than WT OT-II Th9 cells. This effect may be due to the increased frequency of IL- $9^{+}$cells in the OT-II* $\mathrm{Cblb}^{-/-}$Th9 versus WT OT-II Th9 cultures and subsequent downstream effects of IL-9 on other immune cells such as mast cells, NK cells, and other T cells. ${ }^{21}$ As chimeric antigen receptor (CAR) T cells have recently entered the clinical routine and IL-9-producing T9 CAR-T cells have increased antitumor efficacy, additional blocking of Cbl-b could represent a tool to boost Th9 or T9 CAR-T cell polarization while maintaining Treg levels. ${ }^{60-64} \mathrm{Cblb}^{-/-}$mice show much higher expression of IL-9 within tumor tissue, although we could not (due to the extremely low frequency of intra-tumoral Th9 cells) verify Th9 cells as a source of IL-9. CD8 ${ }^{+} \mathrm{Tc} 9$ cells have also been shown to elicit more significant antitumor potential than classical CTLs, an effect that also depends on IL-9 production. ${ }^{65}$ We observed that naive $\mathrm{CD}^{+} \mathrm{T}$ cells under Th9 polarizing conditions developed into Tc9 cells and that the frequency of IL-9 positive cells was significantly higher in a $\mathrm{Cblb}^{--}$background (data not shown). Hence, the source of enhanced IL-9 in tumors growing in $\mathrm{Cblb}^{-/-}$mice is still of debate. Nonetheless, by neutralizing IL-9 in HCmel3 tumor-bearing $\mathrm{Cblb}^{-1-}$ mice, we were able to verify that IL-9 is involved in the tumor-rejection phenotype of these mice. The antitumor effects of Th9 or Tc9 cells involving IL-21 or direct cytotoxicity might, however, additionally contribute to the antitumor effects and were presumably not affected by neutralizing IL-9. Th9 cell-derived IL-21 promotes $\mathrm{CD} 8^{+} \mathrm{T}$ cell proliferation and increases the cytolytic function of NK cells. ${ }^{56}$ Knockout of Cbl-b increased the frequency of tumorinfiltrating $\mathrm{T}$ cells and shifted the $\mathrm{T}$ cell ratio to the dominance of $\mathrm{CD}^{+} \mathrm{T}$ cells over $\mathrm{CD} 4^{+} \mathrm{T}$ and Treg cells. Blocking IL-9 partly reversed this effect, indicating a potential role of IL-9 as a regulator of TIL composition.

In conclusion, our data demonstrate for the first time that Cbl-b critically balances between Th9 cell and Treg cell differentiation by limiting Th9 cell differentiation and $I l 9$ expression, presumably involving BATF3 through the OX40/PI3K pathway. This observation is of in vivo relevance, as resistance to tumor formation and rejection of experimental tumors in $\mathrm{Cblb}^{-/-}$mice is mediated by Th9 cells and IL-9. With regard to the new focus on Th9 cells or T9 CAR-T cells as T cell subsets with a very high antitumor activity, Cbl-b, already previously proposed as an immune checkpoint regulator and objective for therapeutic intervention in tumor therapy, might present 
an attractive target to boost the anti-cancer reactivity of adoptive cellular therapeutics.

\section{Twitter Oliver Schanz @don8719}

Acknowledgements We thank Jasper $\mathrm{G}$ van den Boorn for providing the IgG control antibody for the in vivo tumor experiments.

Contributors Conceptualization, OS, IC, SPY and DW; Methodology, OS, IC, SPY and FSD; Software, FSD; Validation, OS; Formal Analysis, OS, IC, SPY, FSD, SP and TG; Investigation, OS, IC, SPY, FSD, SP and TG; Resources, TG, PK, PB, AH, JL, GB and DW; Data Curation, FSD; Writing, OS and DW; Visualization, OS, IC, SPY and FSD; Supervision, PK, PB, AH, JL, GB and DW; Project Administration, DW; Funding Acquisition, IC and DW.

Funding This work was supported by a grant from 'Deutsche Krebshilfe' (grant No. DKH 70112994).

Competing interests No, there are no competing interests.

Patient consent for publication Not required.

Provenance and peer review Not commissioned; externally peer reviewed.

Data availability statement Data are available in a public, open access repository. Data are available upon reasonable request.

Supplemental material This content has been supplied by the author(s). It has not been vetted by BMJ Publishing Group Limited (BMJ) and may not have been peer-reviewed. Any opinions or recommendations discussed are solely those of the author(s) and are not endorsed by BMJ. BMJ disclaims all liability and responsibility arising from any reliance placed on the content. Where the content includes any translated material, BMJ does not warrant the accuracy and reliability of the translations (including but not limited to local regulations, clinical guidelines, terminology, drug names and drug dosages), and is not responsible for any error and/or omissions arising from translation and adaptation or otherwise.

Open access This is an open access article distributed in accordance with the Creative Commons Attribution Non Commercial (CC BY-NC 4.0) license, which permits others to distribute, remix, adapt, build upon this work non-commercially, and license their derivative works on different terms, provided the original work is properly cited, appropriate credit is given, any changes made indicated, and the use is non-commercial. See http://creativecommons.org/licenses/by-nc/4.0/.

ORCID iD

Oliver Schanz http://orcid.org/0000-0002-1575-1881

\section{REFERENCES}

1 Haabeth OAW, Tveita AA, Fauskanger M, et al. How do CD4(+) T cells detect and eliminate tumor cells that either lack or express MHC class II molecules? Front Immunol 2014;5:p. 174.

2 Veldhoen M, Uyttenhove C, van Snick J, et al. Transforming growth factor-beta 'reprograms' the differentiation of Thelper 2 cells and promotes an interleukin 9-producing subset. Nat Immunol 2008;9:1341-6.

3 Chang H-C, Sehra S, Goswami R, et al. The transcription factor PU.1 is required for the development of IL-9-producing T cells and allergic inflammation. Nat Immunol 2010;11:527-34.

4 Staudt V, Bothur E, Klein M, et al. Interferon-Regulatory factor 4 is essential for the developmental program of T helper 9 cells. Immunity 2010;33:192-202.

5 Lee WH, Jang SW, Kim HS. BATF3 is Suf FI cient for the induction of II9 expression and can compensate for BATF during Th9 cell differentiation. Exp Mol Med 2019;51:1-2.

6 Malik S, Sadhu S, Elesela S, et al. Transcription factor FoxO1 is essential for IL-9 induction in T helper cells. Nat Commun 2017;8:815.

7 Kaplan MH. The transcription factor network in Th9 cells. Semin Immunopathol 2017;39:11-20.

8 Angkasekwinai P, Dong C. IL-9-producing T cells: potential players in allergy and cancer. Nat Rev Immunol 2021;21:37-48.

9 Jiang Y, Chen J, Bi E, et al. TNF- $\alpha$ enhances Th9 cell differentiation and antitumor immunity via TNFR2-dependent pathways. $J$ Immunother Cancer 2019;7:1-12.

10 Zhao Y, Chu X, Chen J, et al. Dectin-1-activated dendritic cells trigger potent antitumour immunity through the induction of Th9 cells. Nat Commun 2016;7:12368.
11 Richard AC, Tan C, Hawley ET, et al. The TNF-family ligand TL1A and its receptor DR3 promote T cell-mediated allergic immunopathology by enhancing differentiation and pathogenicity of IL-9-producing T cells. J Immunol 2015;194:3567-82.

12 Xiao X, Balasubramanian S, Liu W, et al. OX40 signaling favors the induction of $\mathrm{T}(\mathrm{H}) 9$ cells and airway inflammation. Nat Immunol 2012;13:981-90.

13 Chen C-Y, Lee J-B, Liu B, et al. Induction of Interleukin-9-Producing mucosal mast cells promotes susceptibility to IgE-mediated experimental food allergy. Immunity 2015;43:788-802.

14 Turner J-E, Morrison PJ, Wilhelm C, et al. IL-9-mediated survival of type 2 innate lymphoid cells promotes damage control in helminthinduced lung inflammation. J Exp Med 2013;210:2951-65.

15 Micossé C, von Meyenn L, Steck O. Human "TH9" cells are a subpopulation of PPAR-+ TH2 cells. Sci Immunol 2019;4:5943.

16 Eller K, Wolf D, Huber JM, et al. II-9 production by regulatory T cells recruits mast cells that are essential for regulatory $T$ cell-induced immune suppression. J Immunol 2011;186:83-91.

17 Wang Y, Shi J, Yan J, et al. Germinal-Center development of memory B cells driven by IL-9 from follicular helper T cells. Nat Immunol 2017;18:921-30.

18 Takatsuka S, Yamada H, Haniuda K, et al. II-9 receptor signaling in memory B cells regulates humoral recall responses. Nat Immunol 2018;19:1025-34.

19 Schmitt E, Klein M, Bopp T. Th9 cells, new players in adaptive immunity. Trends Immunol 2014;35:61-8.

20 Ramadan A, Griesenauer B, Adom D, et al. Specifically differentiated T cell subset promotes tumor immunity over fatal immunity. J Exp Med 2017;214:3577-96.

21 Rivera Vargas T, Humblin E, Végran F, et al. Th9 cells in anti-tumor immunity. Semin Immunopathol 2017;39:39-46.

22 Chen N, Wang X. Role of IL-9 and STATs in hematological malignancies (review). Oncol Lett 2014;7:602-10.

23 Liu Q, Zhou H, Langdon WY, et al. E3 ubiquitin ligase Cbl-b in innate and adaptive immunity. Cell Cycle 2014;13:1875-84.

24 Bhoj VG, Chen ZJ. Ubiquitylation in innate and adaptive immunity. Nature 2009;458:430-7.

25 Liu Y-C. Ubiquitin ligases and the immune response. Annu Rev Immunol 2004;22:81-127.

26 Naramura M, Jang I-K, Kole $\mathrm{H}$, et al. C-Cbl and Cbl-b regulate T cell responsiveness by promoting ligand-induced TCR down-modulation. Nat Immunol 2002;3:1192-9.

27 Qu X, Miah SMS, Hatani T, et al. Selective inhibition of Fcepsilon $\mathrm{RI}$-mediated mast cell activation by a truncated variant of Cbl-b related to the rat model of type 1 diabetes mellitus. J Biochem 2005;137:711-20.

28 Kitaura Y, Jang IK, Wang Y, et al. Control of the B cell-intrinsic tolerance programs by ubiquitin ligases $\mathrm{Cbl}$ and $\mathrm{Cbl}-\mathrm{b}$. Immunity 2007;26:567-78.

29 Sohn HW, Gu H, Pierce SK. Cbl-B negatively regulates B cell antigen receptor signaling in mature $B$ cells through ubiquitination of the tyrosine kinase Syk. J Exp Med 2003;197:1511-24.

30 Shamim M, Nanjappa SG, Singh A, et al. Cbl-B regulates antigeninduced TCR down-regulation and IFN-gamma production by effector CD8 T cells without affecting functional avidity. J Immunol 2007;179:7233-43.

31 Zhang J, Bárdos T, Li D, et al. Cutting edge: regulation of T cell activation threshold by CD28 costimulation through targeting $\mathrm{Cbl}-\mathrm{b}$ for ubiquitination. J Immunol 2002;169:2236-40.

32 Li D, Gál I, Vermes C, et al. Cutting edge: Cbl-b: one of the key molecules tuning CD28- and CTLA-4-mediated T cell costimulation. $\mathrm{J}$ Immunol 2004:173:7135-9.

33 Krawczyk C, Bachmaier K, Sasaki T, et al. Cbl-B is a negative regulator of receptor clustering and raft aggregation in T cells. Immunity 2000;13:463-73.

34 Reicher B, Joseph N, David A, et al. Ubiquitylation-dependent negative regulation of wasp is essential for actin cytoskeleton dynamics. Mol Cell Biol 2012;32:3153-63.

35 Bachmaier K, Krawczyk C, Kozieradzki I, et al. Negative regulation of lymphocyte activation and autoimmunity by the molecular adaptor Cbl-b. Nature 2000;403:211-6.

36 Chiang YJ, Kole HK, Brown K, et al. Cbl-B regulates the CD28 dependence of T-cell activation. Nature 2000;403:216-20.

37 Paolino M, Thien CBF, Gruber T, et al. Essential role of E3 ubiquitin ligase activity in $\mathrm{Cbl}-\mathrm{b}$-regulated T cell functions. $J$ Immunol 2011;186:2138-47.

38 Chiang JY, Jang IK, Hodes R, et al. Ablation of Cbl-b provides protection against transplanted and spontaneous tumors. J Clin Invest 2007;117:1029-36.

39 Loeser S, Loser K, Bijker MS, et al. Spontaneous tumor rejection by cbl-b-deficient CD8+ T cells. J Exp Med 2007;204:879-91. 
40 Gruber T, Hinterleitner R, Hermann-Kleiter N, et al. Cbl-B mediates TGF $\beta$ sensitivity by downregulating inhibitory Smad7 in primary $T$ cells. J Mol Cell Biol 2013;5:358-68.

41 Paolino M, Choidas A, Wallner S, et al. The E3 ligase Cbl-b and TAM receptors regulate cancer metastasis via natural killer cells. Nature 2014;507:508-12.

42 Qiao G, Ying H, Zhao Y, et al. E3 ubiquitin ligase Cbl-b suppresses proallergic T cell development and allergic airway inflammation. Cell Rep 2014;6:709-23.

43 Landsberg J, Kohlmeyer J, Renn M, et al. Melanomas resist T-cell therapy through inflammation-induced reversible dedifferentiation. Nature 2012;490:412-6.

44 Lutz-Nicoladoni C, Wolf D, Sopper S. Modulation of immune cell functions by the E3 ligase Cbl-b. Front Oncol 2015;5:1-14.

45 Salazar Y, Zheng X, Brunn D, et al. Microenvironmental Th9 and Th17 lymphocytes induce metastatic spreading in lung cancer. J Clin Invest 2020;130:3560-75.

46 Liyasova MS, Ma K, Lipkowitz S. Molecular pathways: Cbl proteins in tumorigenesis and antitumor immunity-opportunities for cancer treatment. Clin Cancer Res 2015;21:1789-94.

47 Stromnes IM, Blattman JN, Tan X, et al. Abrogating Cbl-b in effector CD8(+) T cells improves the efficacy of adoptive therapy of leukemia in mice. J Clin Invest 2010;120:3722-34.

48 Matalon O, Fried S, Ben-Shmuel A, et al. Dephosphorylation of the adaptor LAT and phospholipase $\mathrm{C}-\gamma$ by SHP-1 inhibits natural killer cell cytotoxicity. Sci Signal 2016;9:ra54.

49 Kaplan MH, Hufford MM, Olson MR. The development and in vivo function of T helper 9 cells. Nat Rev Immunol 2015;15:295-307.

50 Wallner S, Gruber T, Baier G, et al. Releasing the brake: targeting Cbl-b to enhance lymphocyte effector functions. Clin Dev Immunol 2012;2012:692639

51 Paolino M, Penninger JM. Cbl-B in T-cell activation. Semin Immunopathol 2010;32:137-48.

52 Elyaman W, Bradshaw EM, Uyttenhove C, et al. II-9 induces differentiation of Th17 cells and enhances function of Foxp3+ natural regulatory T cells. Proc Natl Acad Sci U S A 2009;106:12885-90.
53 Lee W, Kim HS, Hwang SS, et al. The transcription factor Batf3 inhibits the differentiation of regulatory $\mathrm{T}$ cells in the periphery. Exp Mol Med 2017;49:e393.

54 So T, Choi H, Croft M. Ox40 complexes with phosphoinositide 3-kinase and protein kinase B (PKB) to augment TCR-dependent PKB signaling. J Immunol 2011;186:3547-55.

55 Fang D, Liu YC. Proteolysis-independent regulation of PI3K by $\mathrm{Cbl}-$ b-mediated ubiquitination in T cells. Nat Immunol 2001;2:870-5.

56 Chen T, Guo J, Cai Z, et al. Th9 cell differentiation and its dual effects in tumor development. Front Immunol 2020;11:1026.

57 Purwar R, Schlapbach C, Xiao S, et al. Robust tumor immunity to melanoma mediated by interleukin-9-producing T cells. Nat Med 2012;18:1248-53.

58 Hu B, Quu-Lan H, Lei R-E, et al. Interleukin-9 promotes pancreatic cancer cells proliferation and migration via the miR-200a/BetaCatenin axis. Biomed Res Int 2017;2017:2831056.

59 Wan J, Wu Y, Ji X, et al. II-9 and IL-9-producing cells in tumor immunity. Cell Communication and Signaling 2020;18:1-11.

60 Porter DL, Levine BL, Kalos M, et al. Chimeric antigen receptormodified T cells in chronic lymphoid leukemia. N Engl J Med 2011;365:725-33.

61 Ying Z, Huang XF, Xiang X, et al. A safe and potent anti-CD19 CAR T cell therapy. Nat Med 2019;25:947-53.

62 O'Rourke DM, Nasrallah MP, Desai A. A single dose of peripherally infused EGFRvill-directed CAR T cells mediates antigen loss and induces adaptive resistance in patients with recurrent glioblastoma Sci Transl Med 2017;9:984.

63 Maude SL, Laetsch TW, Buechner J, et al. Tisagenlecleucel in children and young adults with B-cell lymphoblastic leukemia. $N$ Engl $J$ Med 2018;378:439-48.

64 Liu L, Bi E, Ma X, et al. Enhanced CAR-T activity against established tumors by polarizing human T cells to secrete interleukin-9. Nat Commun 2020;11.

$65 \mathrm{Lu} \mathrm{Y}$, Hong B, Li H, et al. Tumor-Specific IL-9-producing CD8+ Tc9 cells are superior effector than type-I cytotoxic Tc1 cells for adoptive immunotherapy of cancers. Proc Natl Acad Sci U S A 2014;111:2265-70. 